\title{
3 Research Square

\section{Integrated analysis of land-use, energy and water systems for ethanol production from sugarcane in Bolivia}

Jenny Gabriela Pena Balderrama ( $\nabla$ gabrie@kth.se )

Royal Institute of Technology, KTH

Dilip Khatiwada

Royal Institute of Technology, KTH

Francesco Gardumi

Royal Institute of Technology, KTH

Thomas Alfstad

United Nations Division of Social and Economic Affairs

Silvia Ulloa Jimenez

Stockholm Environment Institute

Mark Howells

Loughborough University https://orcid.org/0000-0001-6419-4957

\section{Article}

Keywords: Biomass, Road Transport Sector, Production Chain Sustainability, Least-cost Optimization Model, Agricultural Intensification

Posted Date: November 11th, 2020

DOI: https://doi.org/10.21203/rs.3.rs-97263/v2

License: @ (i) This work is licensed under a Creative Commons Attribution 4.0 International License. Read Full License 


\title{
Integrated analysis of land-use, energy and water systems for ethanol production from sugarcane in Bolivia
}

J. Gabriela Peña-Balderrama1,2*, Dilip Khatiwada', Francesco Gardumi ${ }^{1,}$, Thomas Alfstad ${ }^{3}$, Silvia Ulloa-Jimenez ${ }^{4}$, Mark Howells ${ }^{5,6}$

1 KTH Royal Institute of Technology, Department of Energy Technology, Stockholm, Sweden; gabrie @kth.se; dilip.khatiwada@energy.kth.se, gardumi@kth.se.

2 Universidad Mayor de San Simón, Facultad de Ciencias y Tecnología, Cochabamba, Bolivia.

3 United Nations Division of Social and Economic Affairs, New York, USA; thomas.alfstad@un.org.

4 Stockholm Environment Institute, Massachusetts, USA; silvia.ulloa@ sei.org.

5 Department of Geography, Loughborough University, UK; m.i.howells@lboro.ac.uk.

6 Centre for Environmental Policy, Imperial College London, UK, m.i.howells@lboro.ac.uk.

* Correspondence: gabrie@kth.se; Tel.: +46-076-408-8437

\begin{abstract}
The use of biomass for renewable energy production is one alternative to reduce the environmental impacts of energy production worldwide. Sugarcane-based ethanol is one of the most widespread biofuels in the road transport sector and its development has been encouraged by strong incentives on production and use in several countries. The growing realization on the environmental impacts of ethanol production indicates the need to increase the efficient utilization of biomass resources by optimizing the production chain sustainably. This paper evaluates enhancements in the ethanol production chain quantitatively by identifying opportunities for agricultural intensification and investments in advanced biorefineries in a least-cost optimization model. Results of our model show that significant cost and environmental benefits can be achieved by modernizing sugarcane agriculture in Bolivia. Demands for ethanol and sugar can be met cost-effectively by increasing sugarcane yields from the current country-average of 55.34 ton/ha to 85.7 ton/ha in 2030 with a moderate cropland expansion of 11.4 thousand hectares in the period 20192030. Our results further suggest that it is cost-optimal to invest in efficient cogeneration in biorefineries to maximize the renewable energy output and the economic benefits of sugarcane ethanol. Finally, biofuel support in the range of 8-10 US $\$ / G J$ is required for investments in second-generation ethanol in biorefineries to be cost-competitive in the medium-term.
\end{abstract}

\section{Introduction}

Biofuels are an alternative for meeting the world's increasing energy needs and can contribute to mitigate greenhouse gas (GHG) emissions and to increase the sustainability of global energy production ${ }^{1,2}$. Depending on the feedstock used for their production, biofuels can be categorized into first, second and third generation. Feedstock for first-generation biofuels are limited to edible crops, such as grains (maize, sorghum and wheat), sugar crops (sugarcane and sugar beet), starch crops (cassava) and oilseed crops (soy, palm, rapeseed) ${ }^{3}$. In contrast, second-generation biofuels are produced from non-edible crops, including lignocellulosic residues from agriculture and forestry ${ }^{4}$. Third-generation biofuels are produced from algae, sewage sludge, and municipal solid wastes ${ }^{5}$.

Worldwide, ethanol is the most widely used biofuel in the transport sector. In 2019, the global ethanol production reached 110.4 billion liters ( $72 \% \mathrm{v} / \mathrm{v}$ of the global liquid biofuel production $)^{6}$ and it is expected to increase to 143 billion liters by $2028^{7}$. Among the main feedstock sources for ethanol production (corn, sugarcane, wheat, sugar beet and sorghum), sugarcane is the most effective option in terms of GHG emissions savings, energy requirements from fossil fuels (energy balance) and land requirements ${ }^{3}$. Sugarcane-based ethanol produced under sustainable conditions has clear advantages over gasoline in reducing GHG emissions and improving air quality in metropolitan areas ${ }^{8}$. Today, ethanol replaces approximately $2 \%$ (in energy basis) of the gasoline consumed worldwide and it is projected to supply the $14 \%$ of global ethanol production by $2028^{6,7}$. 
In order to promote sustainable sugarcane-based ethanol production, several aspects within the supply chain must be assessed. These include feedstock production ${ }^{9-13}$, industrial production of ethanol ${ }^{14-16}$, water quality and availability ${ }^{17-19}$, the energy balance and carbon footprint ${ }^{20-23}$. In this article, important aspects of sustainable ethanol production, viz. agricultural production of sugarcane (e.g. land use, agricultural inputs) and the industrial production of ethanol in biorefineries (e.g. conversion efficiency, costs) are evaluated.

There is a large potential to enhance the environmental benefits of ethanol production from sugarcane by increasing efficiency in the agricultural production chain (increasing yields, restricting biomass residues burning and using abandoned residues/wastes to produce bioenergy, among others) and thereby reducing the environmental impacts ${ }^{3,22,23}$. Reducing the gap between the actual and potential yield can be achieved by reducing growth limiting factors (water and nutrients deficit) and growth reducing factors (pests, diseases, weeds, insects and pollutants) by the use of irrigation, fertilization and the use of agrochemicals, respectively $11,24,25$. Also, agricultural mechanization can contribute to increase productivity on account of timeliness of operations and more efficient utilization of agricultural inputs and labor, providing environmental and economic benefits ${ }^{13,26-28}$.

Higher energy yields and emissions reductions can be achieved for electricity generation and/or second-generation ethanol production through the utilization of lignocellulosic residues, i.e. surplus bagasse and agricultural residues (tops and trashes) ${ }^{14,15,29,30}$. Advanced cogeneration systems lead to a reduction in steam consumption, providing higher electricity generation and export potential compared to traditional cogeneration systems ${ }^{31-33}$. Further process optimization can integrate the biochemical processing of surplus lignocellulosic residues for second-generation ethanol production ${ }^{14,29,34}$. Other alternative technologies to increase the electricity generation potential include the biomass integrated gasifier combined cycle, BIGCC, with further surplus electricity potential of more than $250 \mathrm{kWh} / \mathrm{tc}{ }^{16,35}$.

This study aims to examine potential yield improvements in sugarcane production systems using a tiered approach of agricultural management levels/practices (see Section 3.3) and to evaluate alternative uses of sugarcane biomass residues for bioelectricity and second-generation ethanol production (see Section 3.4). The study performs techno-economic optimization to evaluate cost-optimal upgrades of agricultural production systems and to evaluate the location and size of different biorefinery configurations. A lifecycle approach is performed to compare (in terms of energy inputs/outputs, lifecycle emissions and costs) six agricultural production systems and four biorefinery configurations. In addition, an integrated multi-resource modelling approach allows evaluating pressures on land and water resources. The methodology is tested on a case study assessing biofuel production targets, together with land use, agricultural production, and energy security in Bolivia. The suggested approach is based on open-source modelling tools and can therefore be applied to other countries where biofuel production is under development.

Following this introductory section, context information is provided. Section $\mathbf{2}$ introduces the case study in Bolivia. Section 3 introduces the methods and models used in the analysis. Results are presented and discussed in Section 4. Finally, concluding remarks and policy implications are described in Section 5.

\section{Country context}

To reduce its dependence on liquid fuel imports (diesel and gasoline) and to achieve greater energy security, the government of Bolivia promulgated the Law $\mathrm{N}^{\circ} 1098 / 2018$ to initiate liquid biofuel production and blending. In 2018, an agreement between the government and the private sector (sugar producers) aimed to produce 80 million liters of anhydrous ethanol in that year, with the expectation to reach 380 million liters in $2025^{36}$. The ethanol blending mandate started with $10 \%$ in 2018 and should gradually increase to $25 \%$ by $2025^{36}$. In current agreements, ethanol is to be produced using sugarcane as feedstock, and the ethanol blends are mandated to increase, displacing gradually pure gasoline available in the market.

To reach the production targets, the government of Bolivia estimates to expand the sugarcane cultivated area in 155 thousand hectares in the period 2018-2025, nearly duplicating the 172.6 thousand 
hectares harvested in $2019^{36,37}$. In 2019, the country-average sugarcane yield was 55.3 tons per hectare (t/ha) which is low compared to its average potential yield of $116 \mathrm{t} / \mathrm{ha}^{138}$. In addition, the latest national Census on agriculture indicates that $96.4 \%$ of the sugarcane cultivated is rainfed, therefore sensitive to variations in precipitation. Several producers have narrowed the country-average yield gap with advanced agricultural management practices and increased mechanization. However, further investments in sustainable intensification ${ }^{10,39}$ are required to meet the increasing demands of sugar and ethanol with fewer land resources.

Annually, Bolivia produces over 9.56 million tons of sugarcane on a total area of 172.6 thousand hectares and ranks as the $20^{\text {th }}$ largest producer (in tons) in the world ${ }^{40}$. Figure 1 shows the historical growth of sugarcane harvested area and country-average yield. Small properties $(<10$ ha) represent $14 \%$ of the area, medium-scale properties (10-100 ha) represent 39\%, and large-scale ( $>100 \mathrm{ha}$ ) represent the $47 \%$ of the total cultivated land ${ }^{41}$. There are seven mills in the country, with a total milling capacity of 86 thousand tons of sugarcane per day and a distillation capacity of 250 million liters per year in 2019. Before the promulgation of the Law for Vegetable Derived Additives, hydrous ethanol (92-96\% v/v ethanol) was produced as a secondary product obtained by fermentation of sugar molasses - a residue with low economic value. To meet the short-term mandated biofuel production targets, existing sugar factories (which are also owners of most of the distillation units) have expanded their milling and distillation capacity and implemented molecular sieves to dehydrate hydrous ethanol to produce anhydrous ethanol (99.5 v/v ethanol). However, to meet future production targets, sustainable feedstock, advanced and efficient conversion technologies, and investments in new biorefineries are required.

Anhydrous ethanol can be blended with gasoline up to $25 \%$ (E25) and used in internal combustion engines of most of the modern light-duty automobiles without any modification of the engine or fuel system. Higher blends (e.g. E70, E75, E85, E95, E100 and direct use of hydrous ethanol) are standard fuels for flex-fuel vehicles ${ }^{42}$. Policies for increasing the fleet of flex-fuel cars are not yet being considered in the current policies and therefore excluded in our case-study. Specifically for our case study, our study aims to contribute to policy-making in Bolivia by providing a better understanding on the opportunities on sugarcane agricultural intensification and on investments in efficient conversion technologies in biorefineries.

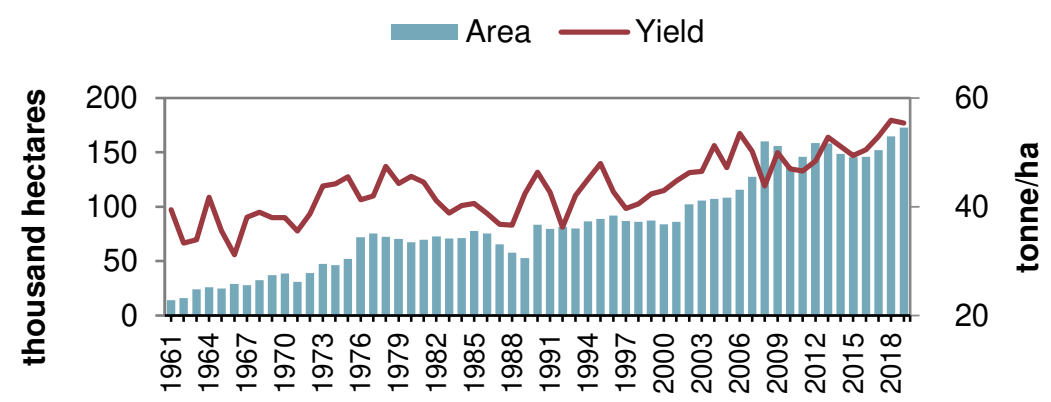

Figure 1. Historical data on the harvested area in primary axis and average yields in the secondary axis

\section{Methods}

\subsection{Modelling framework}

The Open Source Energy Modelling Systems (OSeMOSYS) tool was chosen for our study for its advantages in flexible model formulation and for being fully open-source. The objective function is to minimize the present value of expanding and operating the system components to meet exogenously defined demands. A detailed description of the model can be found in ${ }^{43}$ and a summary of key aspects of the OSeMOSYS model is presented in Section 9.8 in Supplementary Materials.

\footnotetext{
${ }^{1}$ Average agroclimatic attainable yield of current cultivated land considering irrigation and high-input agricultural management from the Global Agro Ecological Zones, GAEZ, project ${ }^{58}$.
} 
Although OSeMOSYS was conceived as a modelling tool for energy systems analysis, its structure allows for modelling any type of system. OSeMOSYS has been widely used in studies of multi-resource integrated systems models (CLEWs), in which interlinkages between land-use systems (L), energy systems (E), water systems (W), and effects of climate (C) are studied in conjunction ${ }^{44}$. A recent literature review by Pereira-Ramos et al. shows 23 CLEWs nexus applications using the OSeMOSYS modelling tool ${ }^{45}$.

In our study, the CLEWs framework was used to assess nexus interactions between the agriculture sector and biorefineries with the water and energy systems. Section 3.7 details the nexus interactions captured in the model.

\subsection{Model timeframe, spatial zonation and system boundaries}

The selected modelling timeframe is from 2013 to 2030, with a temporal resolution of one year. Since the study focuses on evaluating improvements in the agricultural production of sugarcane, the base year is calibrated to represent data found in statistics of the latest National Agricultural Census (year 2013, each agricultural Census is conducted every ten years approximately). The end year is set 5 years after the end of the medium-term ethanol production targets to further explore investment needs in the mediumterm.

Two zonation schemes were combined to divide the territory of Bolivia into a manageable number of regions aiming to capture similar hydrological, climatic, physiographic and agricultural activity characteristics. The first scheme corresponds to the watershed delineation of national Water Balance of Bolivia ${ }^{46}$. The second scheme corresponds to the agro-productive areas from the National Irrigation Plan of Bolivia, which divide the country into 19 regions with similar weather, geography, physiography and agricultural activity ${ }^{47}$. Figure 2 shows the map of the harmonized zonation scheme with 27 regions; additional information on the zonation schemes is presented in Section 9.1 in Supplementary Materials. The regions not suitable for sugarcane production were excluded from the analysis.

Several GIS datasets were collected for the model as described in Section 9.2 in Supplementary Materials. All GIS-data layers were processed to obtain averaged data for each of the 27 regions modelled. Due to the limited spatial representation of our model, our results at micro-scale are necessarily imprecise. However, this study is rather concerned in capturing major geographical differences and providing insights at national-level.

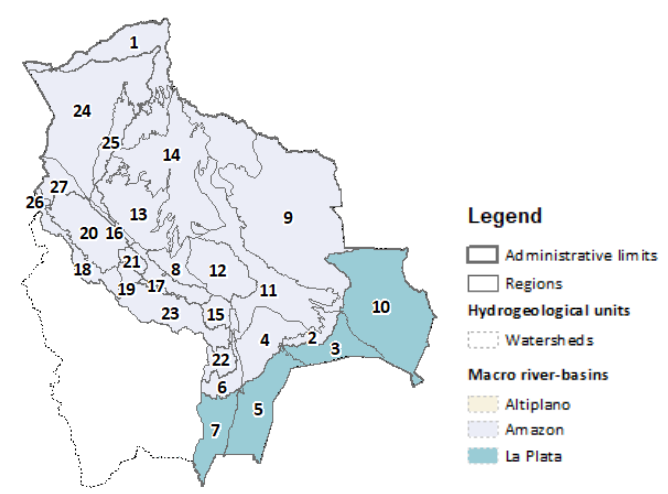

Figure 2. Map of the harmonized zonation scheme with 27 regions. Note that the regions with no sugarcane crop potential were removed from the study.

Figure 3 illustrates the system boundaries considered in the ethanol production assessment. The production chain was divided into two main processes: sugarcane agricultural production and industrial conversion of sugarcane into energy products. The lifecycle costs, energy and emissions were calculated based on data and modelling assumptions for the agricultural and industrial production units, which are described in Sections 3.3 and Section 3.4, respectively. The energy balance and emissions accounting include the energy used and emissions released in the production of agricultural inputs (fertilizers, 
herbicides, pesticides and weed control agrochemicals), industrial supplies (enzyme for hydrolysis of $2 \mathrm{G}$ ethanol) and energy use and emissions associated to human labor. The economic assessment considers only the final costs of labor, agricultural inputs and industrial supplies. Emissions from fuel end-use (as a transport fuel) are not accounted for in the assessment. Energy requirements of diesel and electricity are accounted for at the agricultural production unit, while the industrial production unit produces its own energy and heat requirements through combined heat and power processes (CHP) as described later in Section 3.4. For each of the 27 regions, a separate production chain is modelled. All production chains are linked to produce ethanol for sale in a national market.

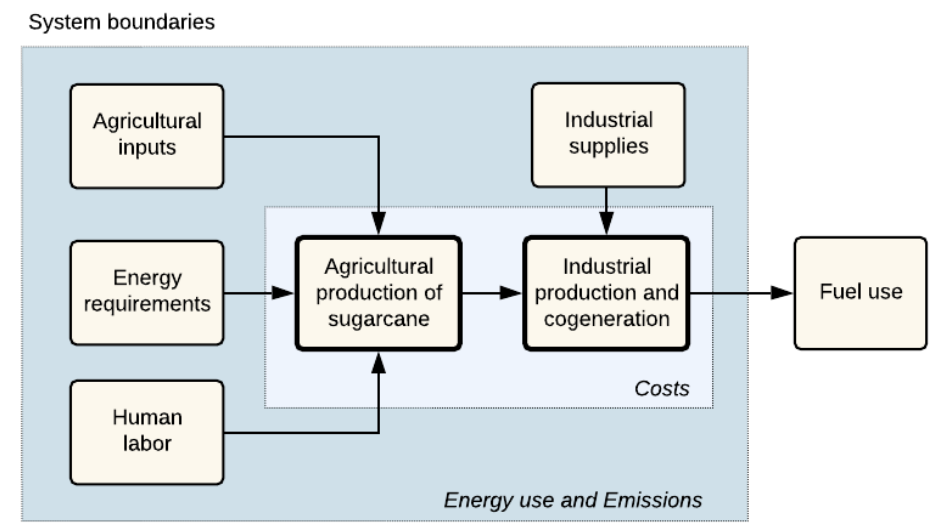

Figure 3. Scheme of the system boundaries used in the ethanol lifecycle assesment

\subsection{Agricultural production modelling}

Four main processes of the sugarcane agricultural production chain are modelled, as illustrated in Figure 4. Sugarcane is a semi-perennial crop with a crop cycle of about 10 to 12 months and a 5 to 6 year production cycle of 5 to 6 years long, also called ratoon culture ${ }^{13,23,27}$. Therefore, the operations of land preparation (soil tillage and seedbed preparation) and seed planting commonly occur every 5-6 years. After this period, sugarcane is replanted. In this work, a ratoon period of 5 years is assumed. Agricultural operations of fertilization, irrigation, and the application of agrochemicals occur every year and these are accounted for in the model per hectare of cultivated land. Harvesting operations and transportation of sugarcane to the mill occur every year and these are accounted for in the model per ton of sugarcane produced.

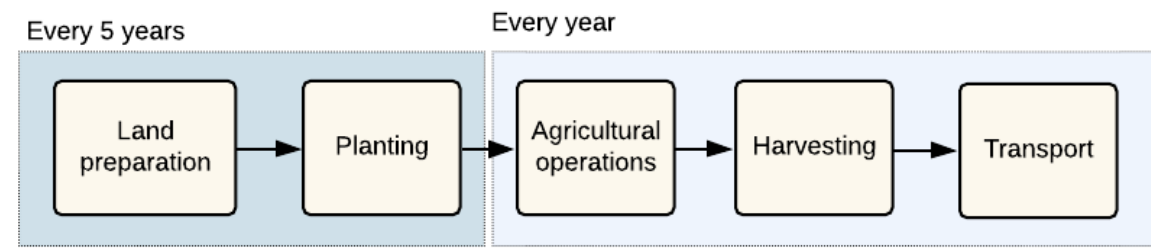

Figure 4. Scheme of the processes modelled in the agricultural production unit

\subsubsection{Costs, energy use and emissions accounting}

For each process described in the agricultural production chain (Figure 4), traditional manualoperations and modern mechanized-operations alternatives are evaluated. This information is later included in the tiers of agricultural production described in Section 3.3.2 to model three levels of mechanization. Mechanical and manual processes involve operations that demand labor, costs and energy and therefore, generate emissions.

Labor requirements in man-hour-ha ${ }^{-1}$ for the manual and mechanized processes were adopted from Yadav et al. for land preparation, planting, harvesting and transportation processes ${ }^{27}$. These are presented in Table-A. 9 in Supplementary Materials. The human labor energy input and emissions were estimated using the Life-style Support Energy (LSSE) system ${ }^{48}$ as adopted by ${ }^{21,49-52}$. The methodology followed is described in Section 9.4 in Supplementary Materials. 
The costs for mechanized and manual production include operational and capital investment costs and these are detailed in Section 9.4.1 in Supplementary Materials. Annualized investment costs and operational costs for machinery required for soil preparation, planting, harvesting and transport operations are obtained from ${ }^{13}$ and detailed in Table-A. 10 in Supplementary Materials. Fuel demands, fuel emissions and fuel prices for machinery operations are detailed in Table-A. 11 in Supplementary Materials. Annualized investment costs and operational costs of irrigation infrastructure (demand and supply) were obtained from ${ }^{53}$ and detailed in Table-A. 16 in Supplementary Materials. More information on the methods to estimate irrigation needs is presented in Section 3.3.4.

Assumptions on optimal use of fertilizers and agrochemical inputs per hectare (pesticides, herbicides, insecticides and weed control) were adopted from ${ }^{23}$. In this study, the energy demand and GHG emissions in the production of fertilizers and agrochemicals are also estimated. Costs of fertilizers and agrochemicals were adopted from national sources ${ }^{54}$. More details and references for the data used are provided in Table-A. 11 and Table-A. 12 in Supplementary Materials.

\subsubsection{Tiers of agriculture production systems}

In developing nations, a variety of agricultural production and management systems typically co-exist in large geographical areas ${ }^{3,55}$. In Bolivia, large heterogeneities are found in sugarcane production, from large-scale and highly mechanized production to small-scale and labor-intensive production ${ }^{56,57}$. Therefore, a characterization of agriculture production systems is necessary for analyzing opportunities for agriculture intensification. In this paper, a typification of three agriculture management and input levels (high, intermediate and low) was adopted from the Global Agro-Ecological Zones, GAEZ, project 58. In the GAEZ approach, soil (and terrain) characteristics and agroclimatic yield-reducing and yieldlimiting factors are associated with crop-productivity at three generic levels of agricultural inputs and management assumptions.

Table 1 summarizes the characteristics of each agriculture production system according to ${ }^{58}$. Under the high input (advanced management assumption), the agriculture production system is mainly marketoriented, with fully mechanized production and uses optimal applications of nutrients and agrochemicals for pest, disease and weed control. The intermediate input (improved management assumption), is partly market-oriented, with partial use of mechanization and use of fertilization and agrochemicals to some extent. The low input (traditional management assumption), is largely subsistence-based, with no use of mechanization, fertilization nor agrochemicals. In total, six agriculture production systems classes are obtained by combining the three input levels with two modes of water supply (rainfed and irrigated). The GAEZ model outputs generate gridded data of agro climatically attainable yields at five arc-minute cell resolution for each agriculture production system which were averaged for each of the 27 regions modelled.

The GAEZ assumptions on labor intensity suggest three levels of use of mechanization: no mechanization (intensive use of labor - low inputs), partial use of mechanization (medium use of laborintermediate inputs) and fully mechanized production (low use of labor- high inputs). Although the level of mechanization does not influence the yield (as use of fertilization, irrigation and agrochemicals), it influences the cost, energy use and emissions of the production. Therefore, we have introduced assumptions on mechanization in the processes described in Figure $\mathbf{4}$ to approximate each management level assumption.

A classification methodology was used to differentiate three levels of mechanization in sugarcane crops in Bolivia using data from the Agricultural Census. The methodology and results are described and discussed in Section 9.3 in Supplementary Materials. The outputs of the classification are used to calculate the areas of each agriculture production system in each region of the model for the base year. We acknowledge that changes in these assumptions will influence the cost-optimization results. The assumptions made, however, derive from statistically-validated classification methods based on current best available data for the country. Section 9.4 in Supplementary Materials shows how the cost, energy 
use and emissions are calculated for every region for high, intermediate and low inputs production systems.

Table 1. Agriculture production systems by input levels and management assumptions ${ }^{58}$

\begin{tabular}{llll}
\hline Features & Low & Intermediate & High \\
\hline Management assumption & Traditional & Improved, semi-mechanized & Advanced, fully mechanized \\
$\begin{array}{l}\text { Production assumption } \\
\text { Cultivars }\end{array}$ & Subsistence oriented. & Partially market-oriented. & Commercial production. \\
$\begin{array}{l}\text { Labor intensity } \\
\text { Mechanization }\end{array}$ & Traditional & Improved varieties & High-yielding varieties \\
$\begin{array}{l}\text { Use of fertilizers, pesticides, } \\
\text { herbicides and weed control. }\end{array}$ & Intensive & Medium & Low \\
Water supply* & No mechanization & Semi-mechanized & Mechanized \\
\hline
\end{tabular}

* Five modes of water supply are available in the GAEZ model, rainfed, rainfed with soil moisture conservation, gravity irrigation, sprinkler irrigation and drip irrigation. For simplicity, data for generic rainfed and irrigated modes from GAEZ are used in this study.

\subsubsection{Yield gap and agro-climatically attainable yields}

Since the GAEZ input-level classification only approximates the actual yields of the sugarcane farms classified in each category, differences between actual yields and agro-climatically attainable yields were accounted for using a yield gap factor. A simple approach was used to estimate the yield gap factor as shown in Section 9.6.3 in Supplementary Materials.

\subsubsection{Irrigation}

To estimate the water requirements for sugarcane irrigation, we adopted the Guidelines for computing crop water requirements from FAO (Paper 56- Irrigation and drainage) ${ }^{59}$. The crop water needs are estimated at monthly-basis using the crop-coefficient approach (Equation 1) whereby the effect of weather conditions are incorporated into the reference crop evapotranspiration (Eto) and crop characteristics into the Kc coefficient.

$$
E T_{c}=E T_{o} \cdot k_{c}
$$

Equation 1

Estimates of the reference crop evapotranspiration were carried out in previous work and published in the national Water Balance of Bolivia, WBB ${ }^{46}$. Results for the $E T_{o}$ from the WBB at basin-level and specific to each land-cover type were aggregated into the 27 regions of our model (and for each landcover type modelled). The hydrological balances of the WBB were developed using the Water Evaluation and Planning System, WEAP from the Stockholm Environment Institute. In this study, the Soil Moisture hydrological model was used and the $E T_{o}$ was calculated using a modified version of the PenmanMonteith equation ${ }^{60,61}$. Section 9.4.4 in Supplementary Materials describes in detail the methods and data used to estimate the monthly crop water needs together with data on costs and energy requirements of irrigation systems.

\subsection{Industrial production modelling}

Typically, the sugar and ethanol industry produce their electricity and heat requirements using bagassebased combined heat and power (CHP) cogeneration plants ${ }^{33}$. However, much more electricity could be produced from the fibrous residues in high-efficient cogeneration, and second-generation ethanol can be produced by biochemical processes ${ }^{14,30,32,34}$. Looking at recent advances in energy production in the sugarcane industry, a distinction can be made between so-called conventional, or traditional biorefineries, and advanced/ efficient biorefineries. Figure 5 illustrates a simple scheme of the biorefinery configurations assessed. More technical information regarding each configuration is provided in Sections 3.4.1 and 3.4.2 and in Section 9.5 in Supplementary Materials.

Conventional biorefineries burn bagasse inefficiently in low-pressure boilers $\left(30\right.$ bar, $340^{\circ} \mathrm{C}$ ) and generate electricity in backpressure steam turbines (BPST), as means of biomass excess disposal rather than for efficient energy generation ${ }^{30,32}$. Excess bagasse in traditional factories is often used to feed 
livestock or dried to be used as litter for pigs and poultry ${ }^{62}$. Today, advanced cogeneration systems are implemented with high-pressure direct combustion systems $\left(80-105\right.$ bar, $\left.480-525^{\circ} \mathrm{C}\right)$ in the form of condensing-extraction steam turbines (CEST). These systems provide higher electricity generation and export potential compared to low-pressure BSPT systems - $150 \mathrm{kWh}$ per ton of sugarcane (tc) compared to $26 \mathrm{kWh} / \mathrm{tc}^{31-33}$.

Among sugarcane producing countries, bagasse availability varies from $23 \%$ to $37 \% \mathrm{w} / \mathrm{w}$ of the sugarcane production (at 48\%-50\% moisture content) ${ }^{63}$. Apart from bagasse, the leaves and tops residues, commonly referred to as "cane trash" are often left in the field and burned after the sugarcane harvesting. The amount of trash corresponds to about $140 \mathrm{~kg}$ of dry matter per ton of sugarcane production ${ }^{64}$. About half of the total sugarcane trash available on the field can be recovered for energy uses at the moment of harvesting ${ }^{64,65}$. The other half is left at the fields to maintain the soil quality ${ }^{64}$. Section 9.5.1 in Supplementary Materials summarizes the main parameters adopted in the simulation of $1 \mathrm{G}$ ethanol production.

Sugarcane residue (tops and leaves) can be used together with bagasse in cogeneration plants. In addition, biorefineries can integrate the biochemical processing of surplus lignocellulosic residues for second-generation ethanol production. Several technological developments for $2 \mathrm{G}$ production process are available in the literature with ethanol yields ranging from 20 to 40 liters/tc $14,29,34,66$.

\section{CONVENTIONAL BIOREFINERY}
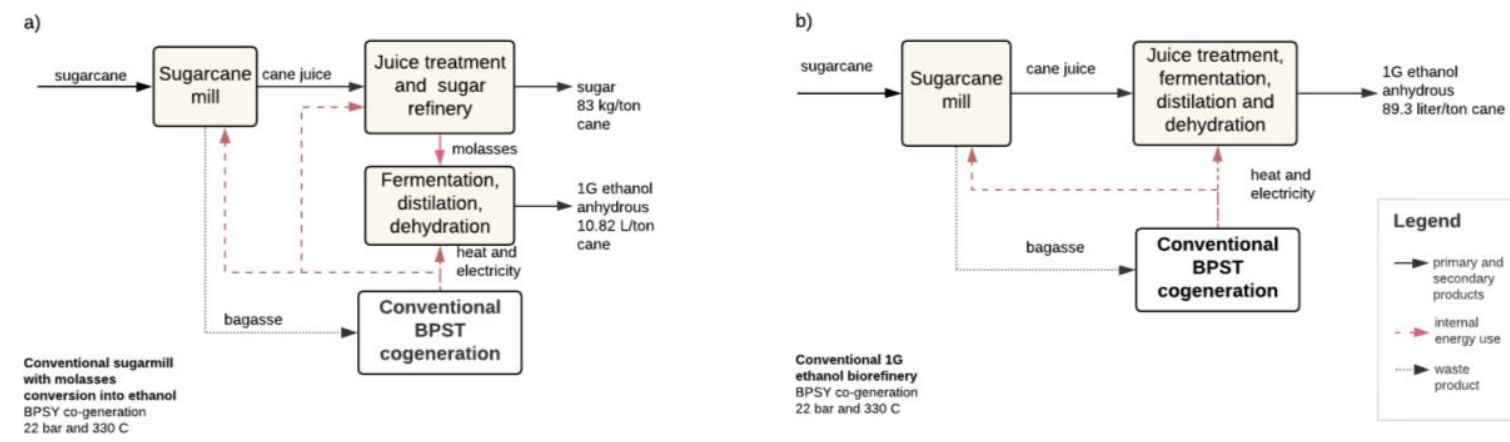

\section{ADVANCED/EFFICIENT BIOREFINERY}$$
\text { c) }
$$
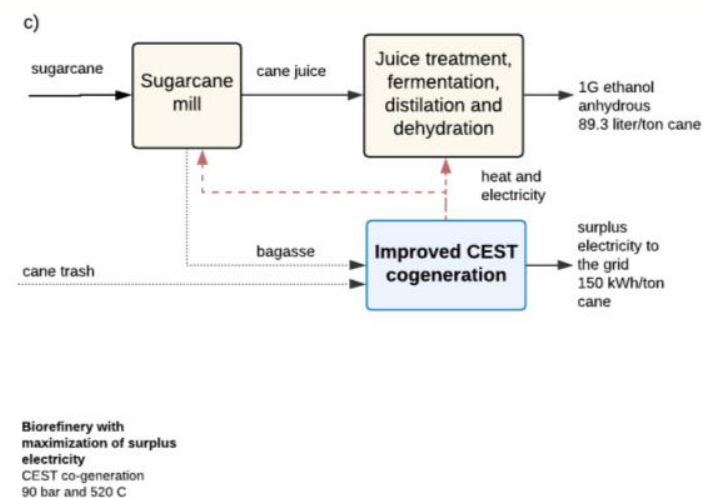

d)

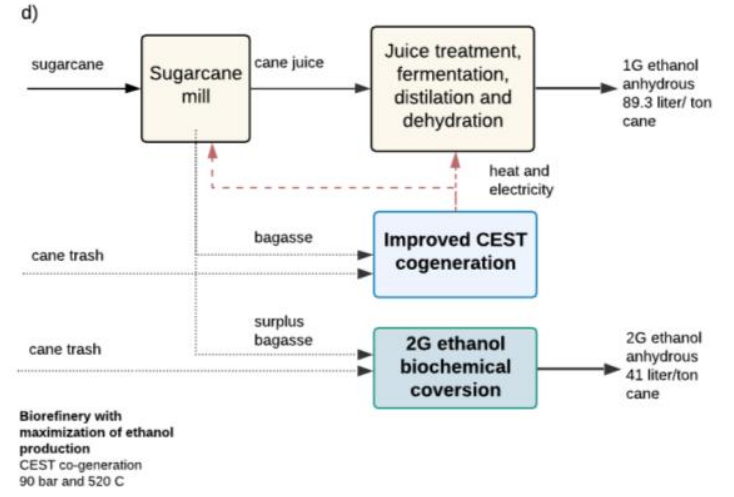

Figure 5. Biorefinery technological options. a) Biorefinery for $1 \mathrm{G}$ ethanol production using sugarcane molasses, conventional $\mathrm{CHP}$ plant (no sugarcane trash recovery), b) Biorefinery for $1 \mathrm{G}$ ethanol production using sugarcane juice, conventional CHP plant (no sugarcane trash recovery), c) Biorefinery for $1 \mathrm{G}$ ethanol production with efficient CHP and export of surplus electricity generation (50\% of sugarcane trash recovery), d) Biorefinery for $1 \mathrm{G}$ and $2 \mathrm{G}$ ethanol production with efficient CHP (50\% of sugarcane trash recovery).

Further details on the conversion chain are detailed in Section Error! Reference source not found. in Supplementary Materials

\subsubsection{Conventional Biorefineries}

Existing sugar factories in Bolivia produce refined sugar as a primary product while hydrated ethanol is produced as secondary product deriving from molasses fermentation and distillation ${ }^{67-69}$. Other recently built biorefineries in Aguaí and Guabirá produce anhydrous ethanol directly from sugarcane juice ${ }^{69,70}$. Conventional biorefineries produce heat and electricity to meet internal energy requirements using 
conventional cogeneration. For simplicity, the small amount of surplus electricity generated (in the range of $10-26 \mathrm{kWh} /$ ton cane) ${ }^{22}$ is neglected in our study.

Although some sugar factories operate in flexible conditions - by adjusting their production of sugar and ethanol to market and supply/demand conditions ${ }^{21}$ - we have introduced fixed production ratios for the sake of simplicity. Conventional technologies for ethanol production were divided into two configurations, as presented in Figure 5.a-b. Detailed information on technical-operation and costs are presented in Section 9.5.3 in Supplementary Materials.

\subsubsection{Advanced biorefinery configurations}

Two advanced configurations were assessed. The first configuration (Figure 5.c) produces $1 \mathrm{G}$ ethanol and uses efficient CHP generating electricity surplus from bagasse and trash combustion to export to the grid. The second configuration (Figure 5.d) uses efficient CHP and biomass (bagasse and trash) residues, which are further converted into second-generation ethanol $(2 \mathrm{G})$. Each configuration uses cane juice to produce ethanol as the primary product. Operational and costs data from a specialized optimization model carried by ${ }^{14,34}$ are adopted and presented in Section 9.5.3 in Supplementary Materials.

\subsection{Residual capacity and New investments in Biorefineries and Agricultural production}

For the base year, 2013, the actual cultivated area and existing biorefinery capacity are introduced as residual capacity. The residual capacity refers to the production capacity invested years before the base year and does not need capital investment costs to operate. Residual capacity operates until the end of the lifetime of the technology. For the agricultural production technologies, the residual capacity is expressed in units of area while for the industrial production technologies, the residual capacity is expressed in energy units (PJ of ethanol produced annually). Investments in new capacity take place when existing capacity is insufficient to meet the demand or when demand can be met more cost-efficiently with new capacity than with the existing one. New investments in available technologies are optimized to minimize the net present value of the entire system.

\subsubsection{Industrial production}

Data on the existing capacity of the different sugar factories and distilleries were collected at facilitylevel and aggregated at regional level. Section 9.5.4 in Supplementary materials shows the data gathered on existing sugarcane milling capacity, sugar production capacity and distillation capacity. An operational lifetime of 25 years was assumed for all biorefinery configurations ${ }^{34}$. In our study, technological upgrades in existing sugar mills ${ }^{15}$ were not assessed.

\subsubsection{Agricultural production}

The outputs of the classification of sugarcane agriculture production systems are used to calculate the residual capacity (in area) in each region for the base year. Section 9.3 in Supplementary Materials details the results of the classification. To account for the lifetime of investments in machinery for agricultural operations, a lifetime of 15 years was used as the average lifetime for the operation of the main machinery. Different to investments in production assets (machinery and tools), investments in agricultural land were not considered depreciable. Therefore, residual capacity and new investments in additional agricultural land were modelled to not have a limited lifetime. This assumption may imply that agricultural land can be reutilized continuously without degrading over time, which may not be completely representative of current agricultural practices ${ }^{71,72}$. A simple linear age-profile was employed to simulate the lifetime of residual capacity in 2013.

\subsection{Demand projections}

In the model, demands are exogenously defined and are price-inelastic. As previously mentioned in Section 3.5, investments in capacity are led by growing demands of end-products such as energy, water and agricultural products. Demand projections are generated using correlations of historical data of endproducts with macro-level growth drivers such as gross domestic product, GDP, and population. 
Investments in sugarcane agricultural production and investments in biorefineries are linked to exogenously-defined demands of ethanol and sugar.

Two demand scenarios are modelled based on different assumptions of GDP and population growth. The Baseline scenario uses GDP and population projections from official sources, and an Alternative scenario uses projections of higher GDP and population growth. For both scenarios, the same government targets for ethanol production (in volume) in the period 2018-2025 are introduced. Note that the introduction of the ethanol-gasoline blend is expected to increase steadily (in percentage in the blend and in volume) while demand for pure gasoline is expected to decline in the period 2018-2025. For the period 2025-2030 ethanol demands are projected in both scenarios assuming that pure gasoline is no longer commercialized by 2030 and is replaced by E25. To simulate a larger penetration of ethanol, the alternative scenario includes a switch to E85 by 2030 in half of the freight-transport sector. Section 9.6 in Supplementary Materials details the methodology used to project energy demands in the transport sector and results from the demand projections.

Projections of domestic demand of sugar were calculated by multiplying population by sugar consumption per capita. Projections of average sugar consumption per capita in Latin America and the Caribbean were used from FAO ${ }^{73}$. Bolivia is a self-sufficient sugar producer, and it exported between $10-20 \% \mathrm{w} / \mathrm{w}$ of its domestic consumption between 2010-2019. A lower bound of $10 \%$ and an upper bound of $20 \%$ of its domestic consumption were set for the period 2020-2030. Future exports are determined by cost optimization. Other exogenously defined demand projections (e.g. domestic water demand, livestock water demand and demand of other agricultural products) are detailed in Section 9.6 in Supplementary Materials.

\subsection{CLEWs nexus multi-system approach}

Figure 6 presents a simplified scheme of the model developed with the represented nexus interactions. The main components of each system are represented in boxes, and the flows of energy/water/land resources to secondary, tertiary and to final demands of commodity products are illustrated with arrows. The interlinkages between land-use, water and energy systems are highlighted with thick arrows. Although the main elements of our model are the agricultural production and biorefinery units, new investments and operations of these units are influenced by nexus interactions with the water, energy and land-use systems.

\subsubsection{Interactions with the energy system}

The energy system models the extraction and transformation of fossil and renewable resources to generate electricity, diesel and gasoline. Section 9.9 in Supplementary Materials details the model components for oil refinery and power generation. If domestic resources are not sufficient to meet the domestic energy demands, the model can import these fuels at international market prices. From the energy system, electricity is supplied to water pumping for residential demand, agricultural irrigation and livestock. Investments in the power system affect the cost of electricity production, therefore affecting the cost of agriculture production with irrigation. Electricity surplus generated by biorefineries is connected to the national grid, therefore displacing gas-fired generation. Diesel is supplied to the land-use system to supply machinery use, such as tractors, harvesters and mechanical planters.

\subsubsection{Interactions with the water system}

The water system was modelled using results from the WBB ${ }^{74}$. The WBB model uses data from 1980 to 2016 to generate the water balances at basin-level (96 basins modelled). The water balance for each region was calculated by overlaying the water inflows and outflows of the basins contained. The components represented in our model are precipitation, evapotranspiration, groundwater recharge and run-off water. Each component is introduced as a ratio of water to area, and it is specific for each landcover type. Results of the hydrological model for the years 2013, 2014, 2015 and 2016 were introduced directly while averages of the last ten years were used as constant values for the period 2017-2030. Section 9.9.2 in Supplementary Materials describes the water model more in detail. 
Effects of climate change will affect the water-balance ratios and rainfed crop-yields in future years; however, these effects were out of the scope of our study. Surface and groundwater available in each region are used to supply domestic water use, crops irrigation and water for livestock.

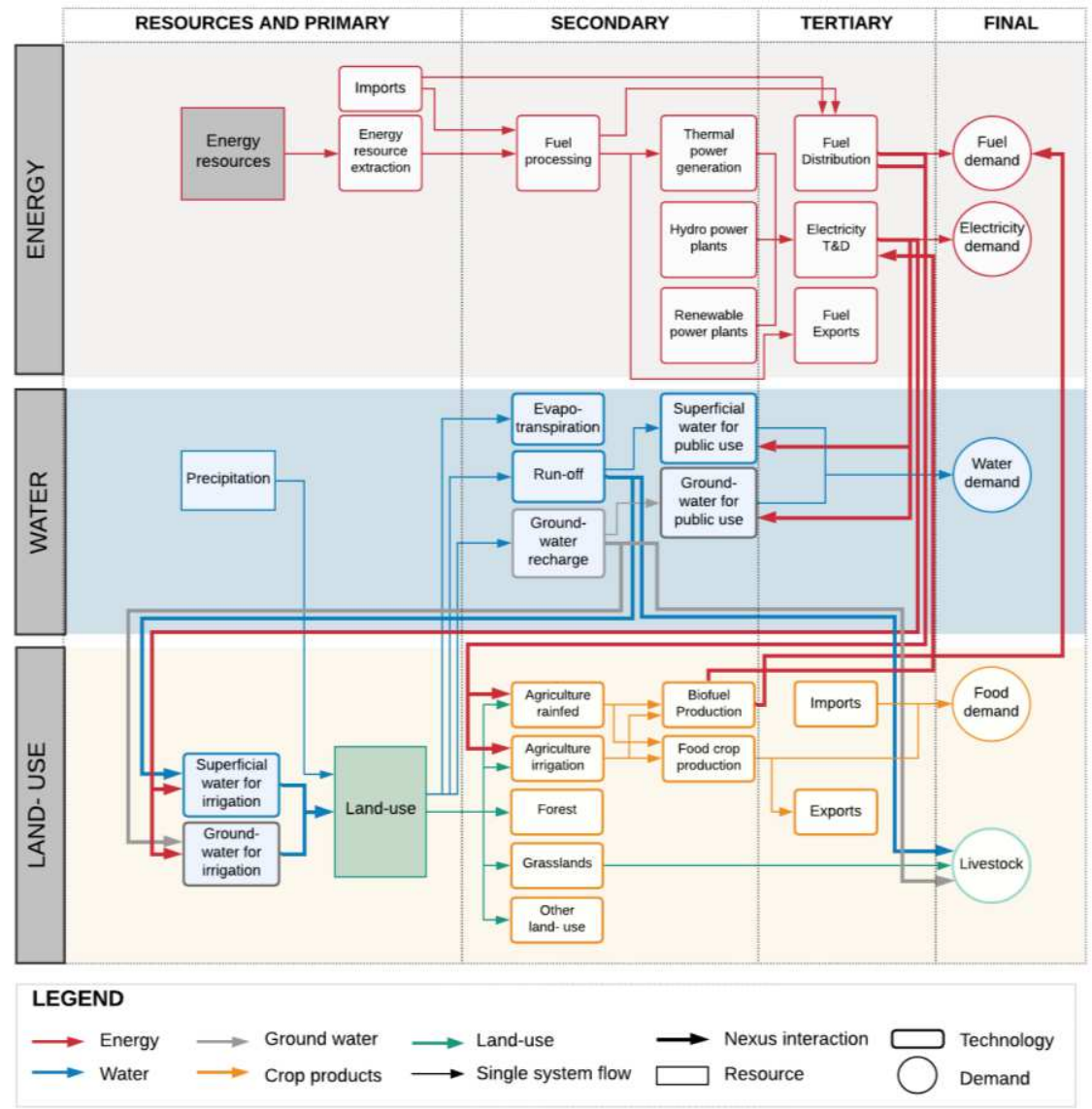

Figure 6. Simplified representation of the systems modelled and the nexus interactions.

\subsection{Net energy analysis of ethanol production}

For each biorefinery configuration, the lifecycle cost, emissions and energy use are compared. The feedstock supply chain (agricultural production) is incorporated in the assessment for high, intermediate and low input agricultural management levels. The timeframe for the lifecycle inventory is 15 years, which accounts for the average lifetime of the machinery - and accounts for 3 ratoon periods of five years. Figure 3 illustrates the system's boundaries for the lifecycle inventory.

Three indicators are used to compare the energy balance of ethanol production for the four technology options. The net energy value (NEV), net renewable energy value (NREV), energy ratio (ER). The net energy value (NEV) of bioethanol is the difference between the energy content of the bioethanol produced and the total primary energy inputs (fossil plus renewable) in the entire biofuel production chain. A positive NEV implies that more energy is extracted from the fuel than is consumed during the production of the fuel. NREV is similar to NEV. The major difference is that only fossil fuel consumption is considered as input. A positive NREV implies that more energy is extracted from the fuel than the amount of fossil energy consumed. ER is the ratio of LHV of ethanol to the fossil energy required to produce it ${ }^{20}$. Table 2 describes the formulas used to calculate each indicator.

Table 2. Formulas for each energy balance indicator

\begin{tabular}{lll}
\hline Indicator & Units & Formula \\
\hline NEV & $(\mathrm{MJ} / \mathrm{l})$ & $\mathrm{NEV}=\mathrm{LHV} \mathrm{EtOH}-\left(\mathrm{E}_{\text {Renewable }}+\mathrm{E}_{\text {fossil }}\right)$ \\
$\mathrm{NREV}$ & $(\mathrm{MJ} / \mathrm{l})$ & $\mathrm{NREV}=\mathrm{LHV} \mathrm{EtOH}_{\text {fossil }}$
\end{tabular}




\subsection{Scenarios modelled}

\subsubsection{Sensitivity scenarios}

Different scenarios were developed to study the effect of selected parameters in the model results. Table 3 shows the details of the scenarios developed. Scenario 0 (SC0) is the base scenario to which the other scenarios are compared. Differences in the model results are investigated by scenarios isolating effects and scenarios combining effects.

Decisions on imports and exports are based on costs. Since the decisions to import or export are sensitive to international market prices, sensitivity scenarios were carried out for two scenarios of high and low international commodity prices. Imports occur only if the imported price is lower than than the domestic production cost and if the domestic production does not have a minimum operating level. If enough domestic resources and processing capacity are available to produce a given commodity, exports are allowed only if the export price is higher than the production costs. For anhydrous ethanol, the model determines whether it is more cost-effective to produce this domestically (with the required investments and costs on feedstock production and industrial production) or to import it at international prices. Section 9.10 in Supplementary Materials shows the international prices projections for crude oil, ethanol anhydrous, ethanol hydrous and sugar to 2030 together with the alternative (high and low) scenarios.

Another parameter worth investigating is access to irrigation. Investments in irrigation infrastructures are financed mainly by public funds and to a lesser extent by public-private joint initiatives. The government has set the target to reach 1 million hectares of irrigated agricultural land by $2030{ }^{75}$. Since specific targets per crop type are not specified, assumptions were made over the expansion on irrigation by 2030. In the base scenario, it is assumed that half of the sugarcane area in the base year will get access to irrigation by 2030 . In addition, a high and low irrigation scenario were evaluated targeting double and half the irrigated area of the baseline scenario, respectively.

\subsubsection{Biofuel support scenarios}

Due to the higher investment required for advanced cogeneration and $2 \mathrm{G}$ ethanol production, lifecycle economic analysis is required to determine the economic feasibility of using surplus biomass as feedstock. In developing nations, additional potential for revenue generation is the sale of Certified Emissions Reductions (CERs) under the Clean Development Mechanism (CDM) of the Kyoto Protocol 76,77. A CER is a carbon credit (equal to one metric ton of $\mathrm{CO}_{2, \text { eq }}$ ) obtained in a project to reduce carbon emissions and can be sold on the carbon market to entities in developed countries for them to achieve their carbon reduction targets. Therefore, biofuel support scenarios are modelled by introducing an additional potential for revenue generation, which is modelled as negative variable costs introduced per every GJ of $2 \mathrm{G}$ ethanol produced. Five scenarios are modelled with biofuel support of 5,7,8,9 and10 US\$GJ.

Table 3. Scenarios modelled

\begin{tabular}{llllll}
\hline Scenario & $\begin{array}{l}\text { Fuel/commodity } \\
\text { prices }\end{array}$ & $\begin{array}{l}\text { Energy } \\
\text { demand }\end{array}$ & Irrigation targets & $\begin{array}{l}\text { Biofuel } \\
\text { support }\end{array}$ & Purpose \\
\hline Sc0 & Baseline & Baseline & Baseline & Baseline & Base scenario \\
Sc1 & High & Baseline & Baseline & Baseline & Isolating Effects \\
Sc2 & Low & Baseline & Baseline & Baseline & Isolating Effects \\
Sc3 & Baseline & Alternative & Baseline & Baseline & Isolating Effects \\
Sc4 & Baseline & Baseline & High & Baseline & Isolating Effects \\
Sc5 & Baseline & Baseline & Low & Baseline & Isolating Effects \\
Sc6 & High & Alternative & High & Baseline & Combining \\
& High & Alternative & Low & Baseline & Combining \\
Sc7 & Baseline & Baseline & Baseline & $5,7,8,9,10$ & Effects \\
& & & & USD/GJ & Isolating Effects \\
Sc8-12 & & & & & \\
\hline
\end{tabular}




\section{Results and discussion}

\subsection{Agricultural production}

A lifecycle accounting of production costs, emissions, energy consumption and sugarcane agriculture was performed for three input management classes. Figure 7 compares the results of the net values calculated for average yields of 100, 70 and 30 tons of sugarcane per hectare (tc/ha) for irrigated highinputs (Hi), intermediate (Ii) and low (Li) inputs production. Note that the values presented in this section will vary for each of the 27 regions when applying region-specific potential yields (see Section 4.2.4). For this illustrative comparison, trash recovery was not included in the production process. The timeframe for the analysis is 15 years, which accounts for the average lifetime of the machinery - and accounts for three ratoon periods of five years.

The sugarcane production costs, energy use and emissions presented in Figure $\mathbf{7}$ are well in range with values found in the literature. For example, sugarcane production costs in Brazil are reported in the range of 18-32 US $\$$ tc for yields in the range of 75-100 tc/ha ${ }^{13,34}$. Emissions for high-input sugarcane production are found in the range of 38-43 $\mathrm{kgCO} 2$,eq/tc for an average yield of $80 \mathrm{tc} / \mathrm{ha}$ in ${ }^{13,22}$. Energy use for highinput sugarcane production is found with an average of $154 \mathrm{MJ} / \mathrm{tc}$ for a yield of $86.4 \mathrm{tc} / \mathrm{ha}^{22}$.

For the average yields considered, the lifecycle costs of one ton of sugarcane produced with Hi is $27 \%$ less costly than for Ii production and $61 \%$ less costly than Li production. The differences are attributed to the manual operations (labor), which have a larger share of Ii and Li. Although the production costs per unit of harvested area are higher for $\mathrm{Hi}$ (21\% and 29\% higher compared to Ii and Li), the costs per ton of sugarcane turn to be lower for Hi due to higher yields achieved.

The lifecycle emissions of one ton of sugarcane produced with Hi are 4\% and $13 \%$ lower than Ii and Li production. Agriculture inputs, trash burning and decomposition and transportation are the most significant contributors to emissions in $\mathrm{Hi}$ and Ii production, accounting for $69 \%$ and $66 \%$ of total emissions, respectively. For Li production, associated emissions to manual harvesting, trash burning and decomposition contribute to $62 \%$ of the total emissions. Lastly, the lifecycle energy use to produce a ton of sugarcane with $\mathrm{Hi}$ is $18 \%$ and $42 \%$ lower than $\mathrm{Ii}$ and $\mathrm{Li}$, respectively. The largest contributor to $\mathrm{Li}$ and Ii is the energy use associated with human labor, while mechanized processes lead the energy consumed in Hi production.
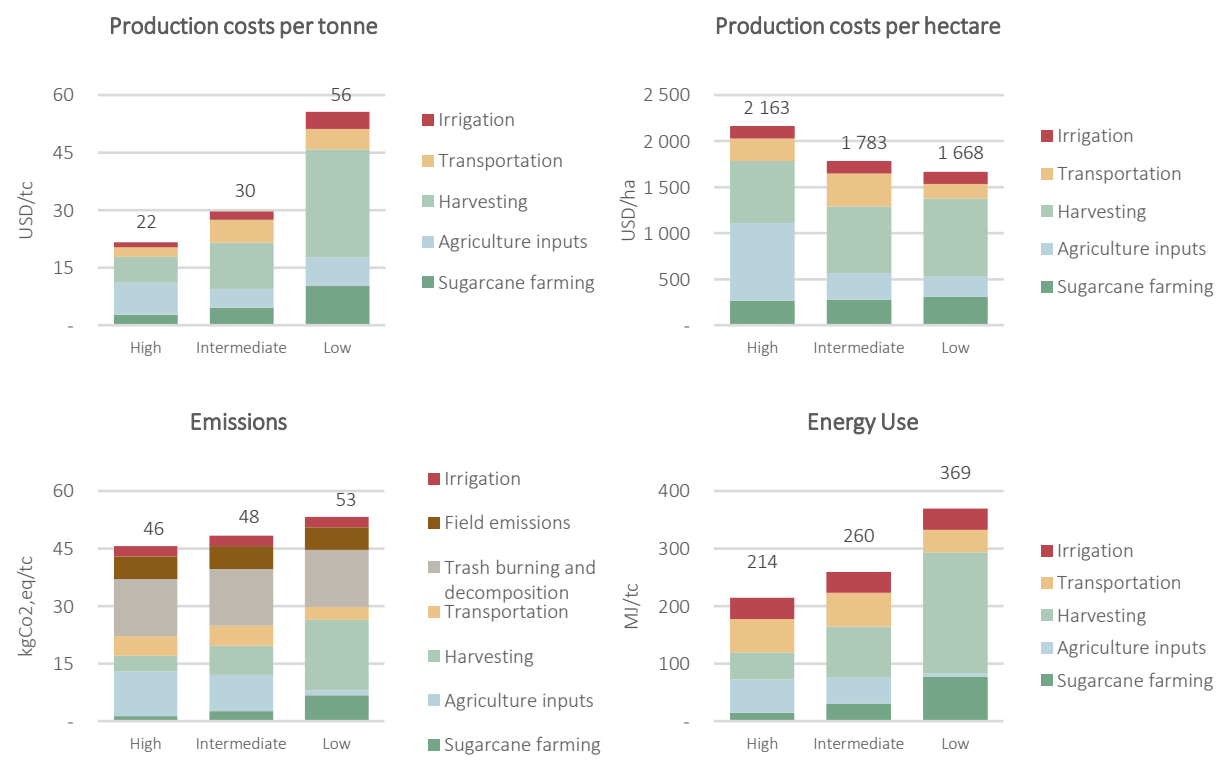

Figure 7. Comparison of the lifecycle production costs per unit of production and per unit of harvested area, emissions and energy use of sugarcane cultivated under high, intermediate and low input levels.

- Note that the cost estimates vary in every region according to their potential yields. Average yields are used in the charts for illustrative purposes: 100 tc/ha for high-inputs, 70 tc/ha for intermediate inputs and 30 tc/ha for low-inputs. Only results for irrigated agriculture are presented. 
- Note that the charts do not show data for production with trash recovery. Additional costs of harvesting and transport are introduced together with reduced emissions estimated in ${ }^{13}$.

To reach the targeted volumes of ethanol production and ethanol blending, the government estimates an annual increase of 18 thousand hectares of cultivated sugarcane area, reaching 2.8 thousand $\mathrm{km}^{2}$ by 2025 (from the current 1.73 thousand $\mathrm{km}^{2}$ in 2019) (YPFB 2018; Nolte 2018). In contrast, results of the optimization show that it is cost-effective to increase feedstock production with less cropland (1.6 thousand $\mathrm{km} 2$ ) and increased yields from the current $55.34 \mathrm{tc} / \mathrm{ha}$ to $76.8 \mathrm{tc} / \mathrm{ha}$ in 2025 and to $85.7 \mathrm{tc} / \mathrm{ha}$ in 2030 (as shown in Figure 8).

The optimization results show that Region 12, located in the western lowlands of Santa Cruz, can maintain an increasing production of sugarcane and reduce its cultivated area by $29 \%$ by increasing the share of high-input irrigated production from 1\% in 2013 to 56\% in 2030. By 2030, Region 12 can produce $53 \%$ of total sugarcane demand in the country compared to $93 \%$ in 2013. The largest expansion occurs in Region 24, located in the northern rainforest of $\mathrm{La} \mathrm{Paz}$, in which the cultivated area increases with highinputs rainfed production. By 2030, Region 24 can supply $25 \%$ of the total sugarcane demand. Region 11 , located in the western lowlands of Santa Cruz, can increase its cultivated area with irrigated intermediate-inputs production, supplying $9 \%$ of the total production in 2030. Region 8 located in the northern-east valleys of Cochabamba can supply 13\% of the total production in 2030 with irrigated highinput production. Lastly, the cultivated area and production in Region 7, located in the southern valleys of Tarija, are reduced compared to 2013 by $83 \%$ and $73 \%$, respectively due to less competitive yields compared to other regions. In Region 7, agricultural land switches from sugarcane to other crops.

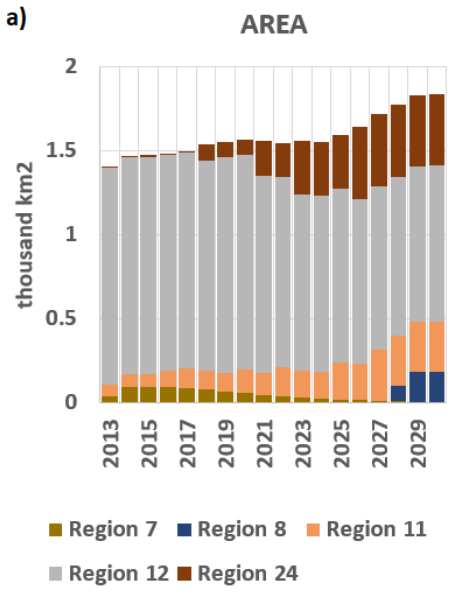

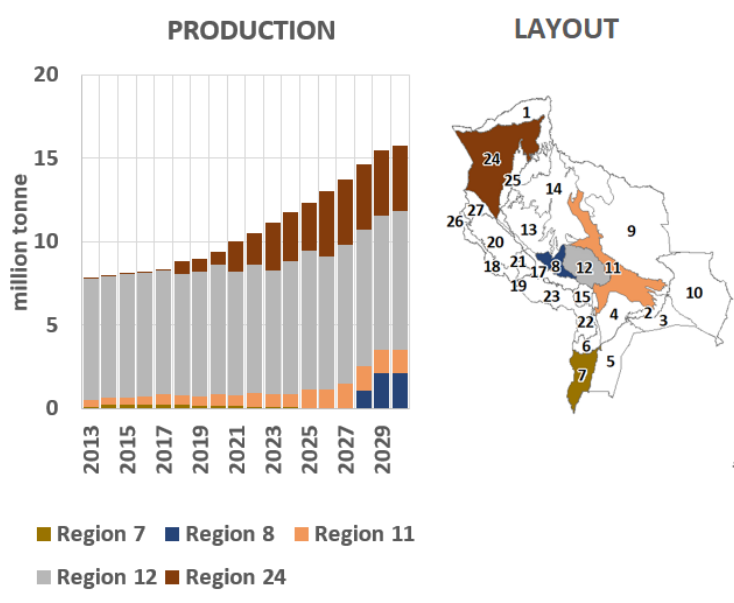

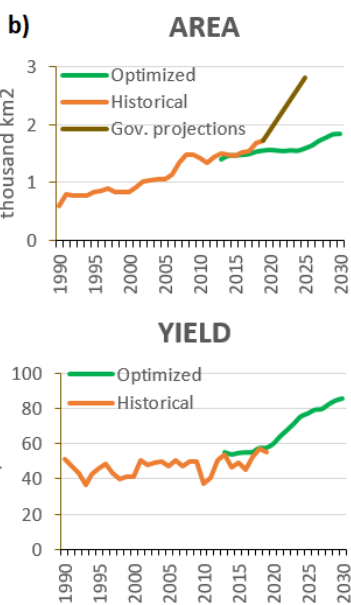

Figure 8. Optimization results for a) Cultivated area in main producing Regions, b) Annual production of main producing regions, c) Comparison of agriculture area national averaged yield between government projections and the optimization results

Figure 9 shows modelling results at the national level, aggregating the results by input level and by water supply modes (rainfed and irrigated). From 2020 the cultivated sugarcane area with high-inputs and irrigation (HI) increases continuously nearly reaching the upper limit of irrigated sugarcane production ( 0.70 thousand $\mathrm{km}^{2}$ from 0.73 thousand $\mathrm{km}^{2}$ of sugarcane cropland with access to irrigation). The cultivated area with intermediate inputs and rainfed (IR) reduces by $38 \%$ in 2030 compared to its area in 2019. The land cultivated with high-inputs rainfed (HR) increases $25 \%$ of its area in 2030 compared to 2019. By 2030, the area under irrigation is $38 \%$ of the total cultivated area and produces $53 \%$ of the total production. Since investments in high-inputs and mechanization allow yield increases, the average sugarcane production costs descend from 26.7 US\$/ton in 2013 to 23.6 US\$/ton in 2030 for sugarcane production with no straw recovery and from 35.2 US\$/ton in 2013 to $28.6 \mathrm{US} \$ /$ ton in 2030 for production with straw recovery. 

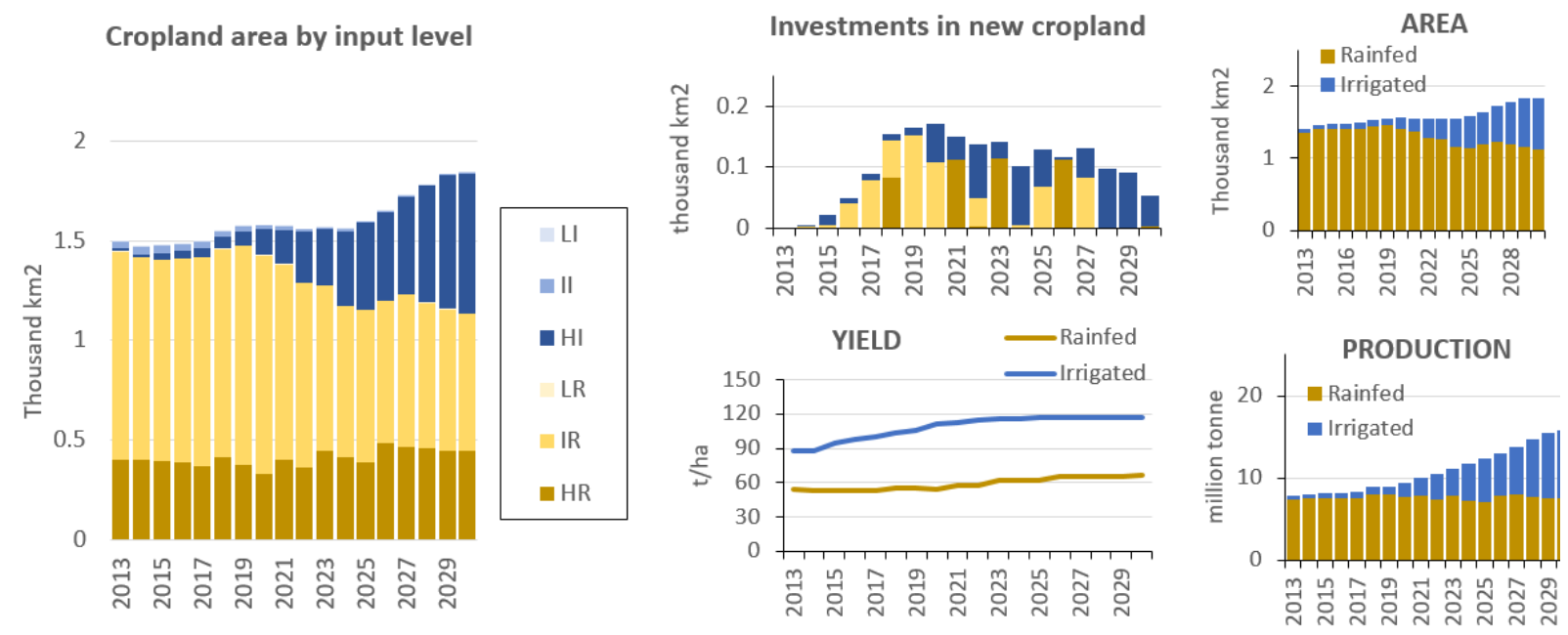

Figure 9. a) Results of the sugarcane agricultural land by input level, b) agricultural land expansion by input level, c) Accumulated area and production for water use per category.

Management input levels acronyms, CDALI (low-inputs with irrigation), CDAll (intermediate-inputs with irrigation), CDARHI (high-inputs with irrigation), CDALR (low-inputs and rainfed), CDAIR (intermediate inputs and rainfed), CDAHR (high-inputs and rainfed).

\subsection{Industrial production}

In this section, a lifecycle inventory for energy consumption, production costs and emissions of the production of one liter of anhydrous ethanol is performed to illustrate the main differences. Figure 10 compares the results of the lifecycle inventories for each of the four biorefinery configurations. The results are differentiated by feedstock production type (input level). For an illustrative comparison, average yields of 100, 70 and 30 ton of sugarcane per hectare (tc/ha) are used for $\mathrm{Hi}$, Ii and $\mathrm{Li}$.

For all biorefinery configurations, the fossil energy used in the production of one liter of anhydrous ethanol is nearly six times lower than the lower heating value of anhydrous ethanol (21.2 MJ/L). Because bagasse and trash (in the advanced biorefinery configurations) is used for energy, there is no demand for fossil fuels in the industrial phase. As a result, there is a strong benefit not only to the energy balance but also in the GHG emissions associated with ethanol production.

For all technologies, fossil energy use is estimated at an average of $3.5 \mathrm{MJ} / \mathrm{L}$, excluding the credits related to electricity surplus. GHG emissions are estimated at an average of $28 \mathrm{gCO}_{2, \mathrm{eq}} / \mathrm{MJ}$ which is almost a third of the emissions of gasoline $\left(81.77 \mathrm{gCO}_{2, \mathrm{eq}} / \mathrm{MJ}\right){ }^{23}$. Regarding costs, feedstock production with low inputs increases the ethanol production costs higher than the international price of anhydrous ethanol in 2020. When feedstock is produced with high and intermediate inputs, total production costs are lower than international prices. 

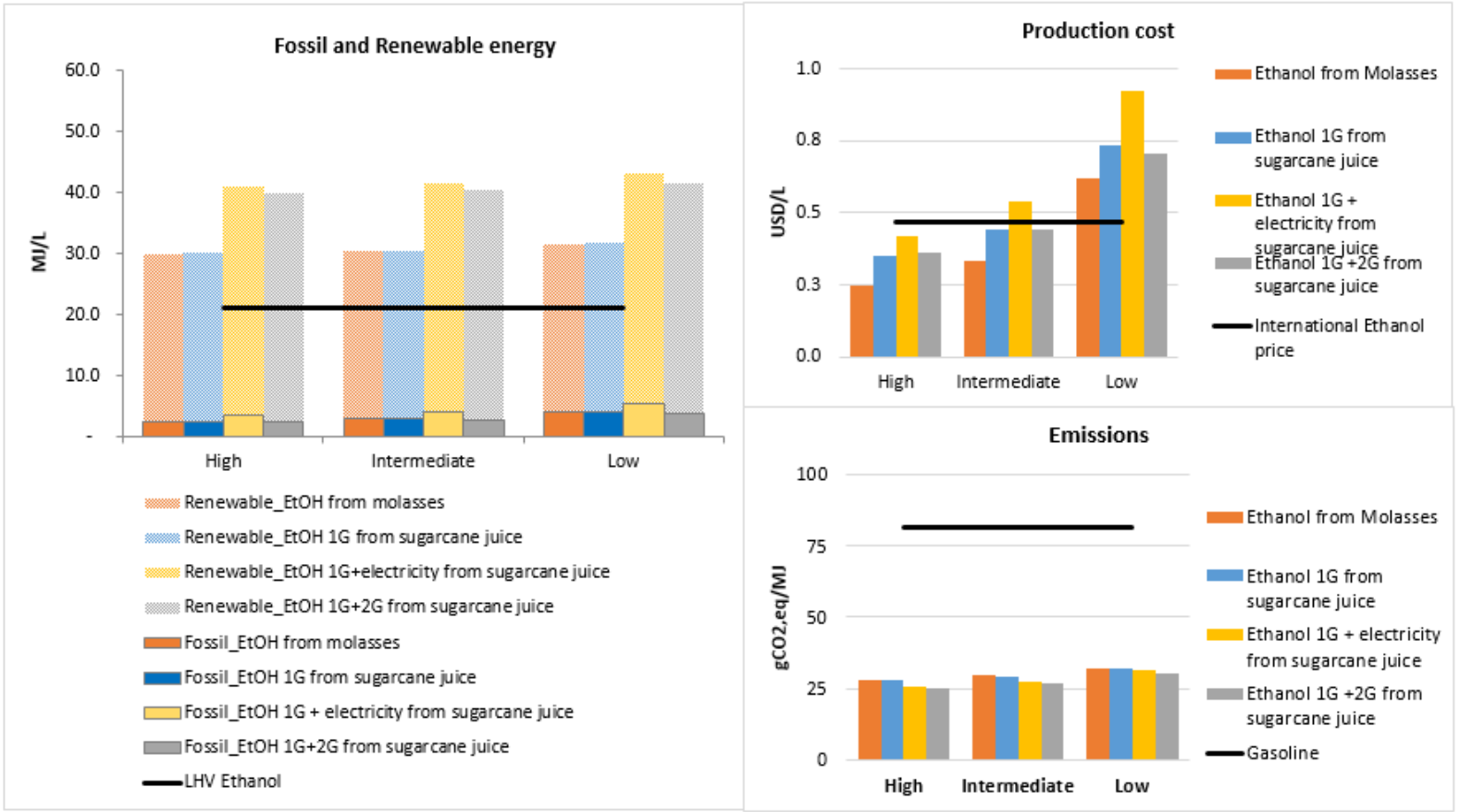

Figure 10. Comparison of the lifecycle energy, production costs and emissions.

- For ethanol produced from molasses, emissions, energy and costs from the upstream operations (cultivation, harvesting and transport) are partitioned as per economic allocation following a methodology illustrated in ${ }^{20}$.

- Note that the values presented in this illustrative example include yields of $100 \mathrm{tc} / \mathrm{ha}, 70 \mathrm{tc} / \mathrm{ha}$ and $30 \mathrm{tc} / \mathrm{ha}$ for high, intermediate and low-input production. The lifecycle costs, energy and emissions presented in this figure will vary for every region due to yield differences for each agricultural production type.

Figure 11 presents a breakdown by the production process of the lifecycle energy use (renewable and fossil), emissions and production costs to produce one litre of anhydrous ethanol using feedstock produced with Hi. For all biorefinery configurations, industrial processing is the most energy-demanding activity. The upstream operations of feedstock production (sugarcane production and transport) are the largest contributors to emissions (see Figure 11). Note that smaller emissions are observed for the advanced biorefineries due to emission reductions for avoided emissions of trash burning and decomposition in the fields. Avoided emissions for electricity surplus sales are accounted for assuming that these displace gasfired generation.

Regarding costs, ethanol production from molasses is the cheaper alternative. However, investments on this alternative are not encouraged since its activity is linked to sugar production. Production costs of ethanol from the $1 \mathrm{G}$-only biorefinery and $1 \mathrm{G}+2 \mathrm{G}$ biorefinery are comparable $(0.35 \mathrm{US} \$ / \mathrm{L}$ compared to $0.36 \mathrm{US} \$ / \mathrm{L})$; however, the $1 \mathrm{G} 2 \mathrm{G}$ alternative has higher total emissions $\left(0.1 \mathrm{kgCO}_{2} / \mathrm{L}\right.$ compared to 0.37 $\mathrm{kgCO}_{2} / \mathrm{L}$ ). In the optimization results, only new investments on the advanced biorefinery for $1 \mathrm{G}+$ electricity occur. This is due to the fact that electricity exports to the grid allow the system to save costs in power generation and on additional investments to increase the generation capacity. By 2030, $1027 \mathrm{GWh}$ of bioelectricity could be exported to the grid (4\% of total generation). Figure 12 shows the annual emissions of ethanol production and the avoided emissions of displaced gasoline and displaced gas-fired thermoelectricity generation. 


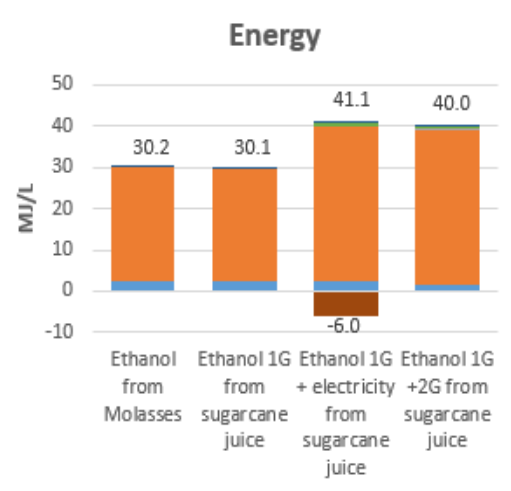

- Electricity surplus sales

Enzyme

- Sugarcane production and transportation

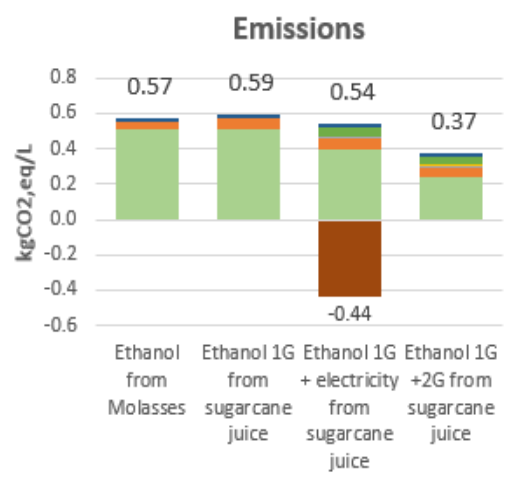

Ethanol transport and distribution

-Trash recovery

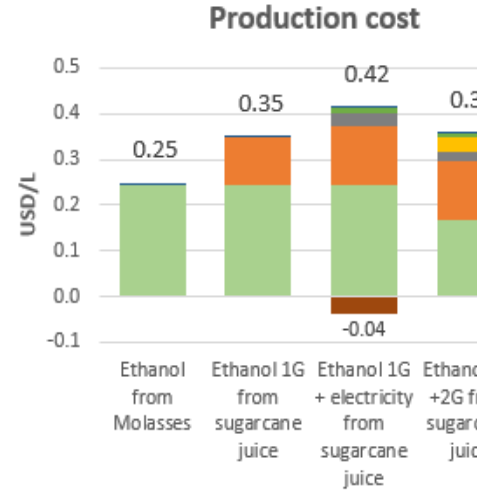

- Trash transport

- Processing to ethanol*

Figure 11. Comparison of the lifecycle energy use, emissions and costs of the four biorefinery configurations. Sugarcane feedstock produced with High inputs with irrigation is used.

Avoided emissions from electricity surplus sales are calculated considering $1.68 \mathrm{kWh} / \mathrm{L}$ EtOH (see the balance in Error! Reference source not found., assuming that bioelectricity displaces gas-fired generation in the grid (emission intensity of $90.93 \mathrm{gCO} / \mathrm{MJ}$ ). Revenues from electricity surplus sales are accounted for considering a revenue at marginal generation costs (16.71 USD/kWh).

\section{EMISSIONS}

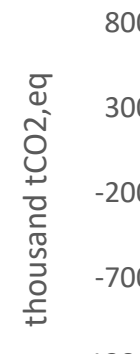

$-1200$

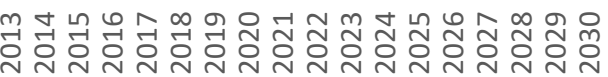

Ethanol transport and distribution

- Processing to Ethanol

- Trash recovery and transport

- Sugarcane production

- Avoided electricity emissions

- Avoided gasoline emissions

Table 4 shows the energy balance indicators for the production of anhydrous ethanol in each biorefinery configuration. A negative value obtained in the net energy value (NEV) indicator means that the energy content of the ethanol produced is lower than the total primary energy inputs (fossil plus renewable) in the entire biofuel production chain. Higher negative values of the NEV show the increased use of biomass residues (sugarcane trash). Positive values of the NREV imply that more energy is extracted from ethanol than is consumed from fossil fuels during the production of one litre of ethanol. Higher values of the energy ratio (ER) imply that more energy is utilized from sugarcane (to generate energy products, $1 \mathrm{G}$ ethanol, $2 \mathrm{G}$ ethanol and electricity) than is consumed from fossil fuels used during the production of ethanol. The advanced biorefinery for $1 \mathrm{G}$ ethanol + electricity is the technology with the highest ER scores.

\begin{tabular}{|c|c|c|c|c|}
\hline & Units & High & Intermediate & Low \\
\hline \multicolumn{5}{|c|}{ Ethanol from Molasses } \\
\hline NEV & $(\mathrm{MJ} / \mathrm{l})$ & -8.7 & -9.2 & -10.4 \\
\hline NREV & $(\mathrm{MJ} / \mathrm{l})$ & 18.6 & 18.1 & 17.0 \\
\hline ER & $\left(\mathrm{MJ}_{\text {tot }} / \mathrm{MJ}_{\text {fossil fuel }}\right)$ & 10.4 & 9.7 & 7.0 \\
\hline \multicolumn{5}{|c|}{ Ethanol $1 \mathrm{G}$ from sugarcane juice } \\
\hline NEV & $(\mathrm{MJ} / \mathrm{l})$ & -8.9 & -9.4 & -10.6 \\
\hline NREV & $(\mathrm{MJ} / \mathrm{l})$ & 18.6 & 18.1 & 17.0 \\
\hline ER & $\left(\mathrm{MJ}_{\text {tot }} / \mathrm{MJ}_{\text {fossil fuel }}\right)$ & 8.1 & 6.8 & 5.0 \\
\hline
\end{tabular}

Ethanol $1 G$ + electricity from sugarcane juice 


\begin{tabular}{|c|c|c|c|c|}
\hline NEV & $(\mathrm{MJ} / \mathrm{l})$ & -13.9 & -14.5 & -16.1 \\
\hline $\begin{array}{l}\text { NREV } \\
\text { ER }\end{array}$ & $\begin{array}{l}(\mathrm{MJ} / \mathrm{l}) \\
\left(\mathrm{MJ}_{\text {tot }} / \mathrm{MJ}_{\text {fossil fuel }}\right)\end{array}$ & $\begin{array}{l}11.7 \\
11.1 \\
\end{array}$ & $\begin{array}{l}11.1 \\
9.5 \\
\end{array}$ & $\begin{array}{l}9.7 \\
7.1 \\
\end{array}$ \\
\hline \multicolumn{5}{|c|}{ Ethanol $1 G+2 G$ from sugarcane juice } \\
\hline $\begin{array}{l}\text { NREV } \\
\text { ER }\end{array}$ & $\begin{array}{l}(\mathrm{MJ} / \mathrm{I}) \\
\left(\mathrm{MJ}_{\text {tot }} / \mathrm{MJ}_{\text {fossil fuel }}\right)\end{array}$ & $\begin{array}{l}18.7 \\
8.6\end{array}$ & $\begin{array}{l}18.3 \\
7.4 \\
\end{array}$ & $\begin{array}{l}17.3 \\
5.5 \\
\end{array}$ \\
\hline
\end{tabular}

\section{1}

\subsection{Biofuel support}

In this section, the effect of $2 \mathrm{G}$ ethanol support in the form of green certificates (CER) or incentives/subsidies is evaluated in terms of investments in new biorefineries. A biofuel incentive smaller than $7 \mathrm{US} \$ / \mathrm{GJ}$ does not have an impact on the investments in new biorefineries. Biofuel support in the range of 8-10 allows half of the new investments to be on the advanced $2 \mathrm{G}$ biorefinery by 2030 . Without the biofuel support (base scenario, $\mathrm{Sc} 0$ ), production of $2 \mathrm{G}$ ethanol is not cost-competitive under the model assumptions. Figure $\mathbf{1 3}$ shows the differences in the accumulated new investments in the period 20132030 for the six biofuel support prices.

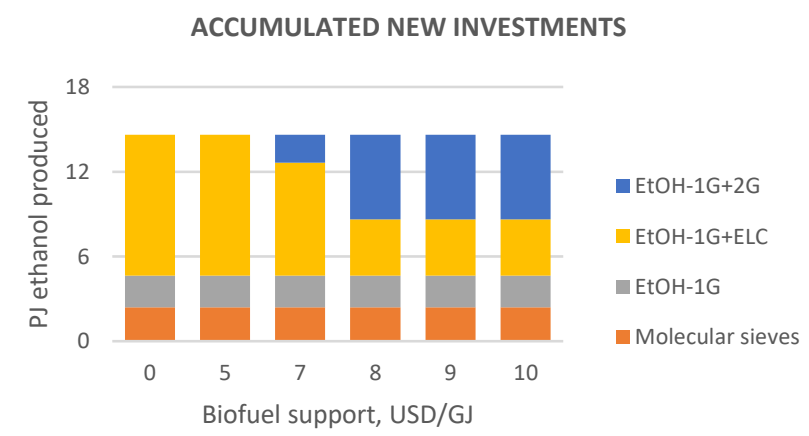

Figure 13. Accumulated energy production (or technology activity) in $\mathrm{PJ}$ and b) accumulated new capacity of biorefineries in units of $\mathrm{PJ}$ of ethanol produced

Note.- Molecular sieves are installed on existing sugarmills producing hydrous ethanol to produce anhydrous ethanol.

\subsection{Sensitivity scenarios}

Scenario 1 isolates the effect of high international prices. Exports of hydrous ethanol are increased in Sc1 compared to the rest of the scenarios, in addition, the cultivated area and production in 2030 are $14 \%$ and $13 \%$ higher than the $\mathrm{Sc} 0$. The effects of low international prices in Scenario 2 allow the imports of anhydrous ethanol and reduces the exports of hydrous ethanol. Higher demands in Scenario 3 lead to 36\% and 24\% higher harvested area and production in 2030 compared to S0. Increased access to irrigation in Scenario 4 leads to increased yields and therefore a reduction in $7 \%$ on the harvested area in 2030 compared to the S0. Conversely, reduced access to irrigation in Scenario 5 leads to yield reductions and an increase in $25 \%$ in the harvested area compared to Sc0.

The combined effects of high international prices, higher demands (alternative scenario) and high irrigation targets in Scenario 6 lead to $8 \%$ increase in harvested area in 2030 compared to Sc0 and 11\% increased imports of anhydrous ethanol. Lastly, the combined effects of high international prices, higher demands and lower irrigation targets lead to an increase in $44 \%$ of the harvested and $6 \%$ higher imports of anhydrous ethanol in 2030. 
a)

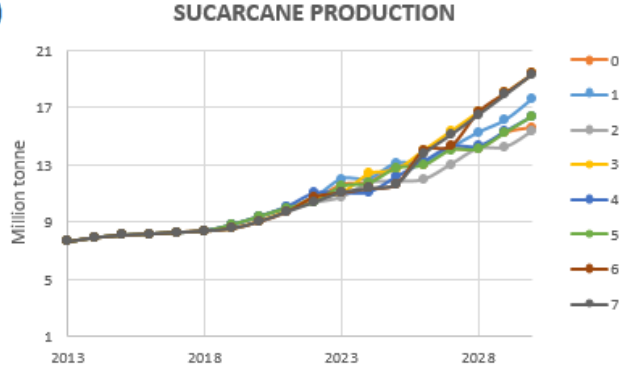

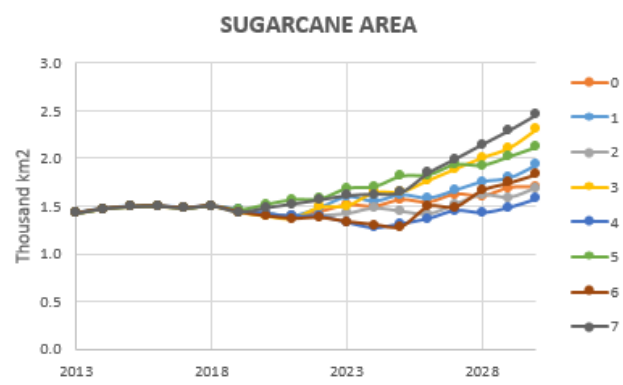

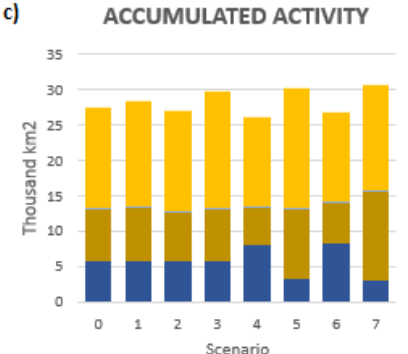

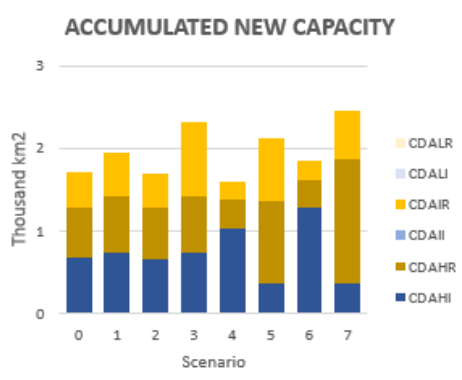

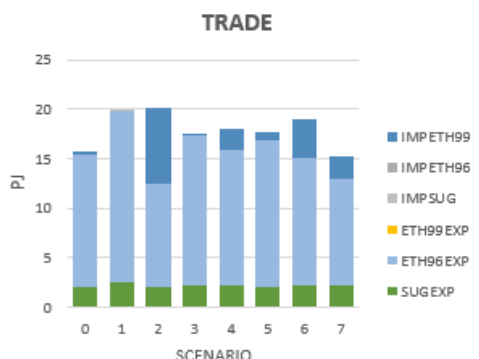

Figure 14. Results from sensitivity scenarios. a) Sugarcane area and production. b) Commodity trade (imports and exports). c) Accumulated harvested area (activity) by input level and accumulated new investments by input level (new capacity)

\section{Conclusions}

Bolivia can cost-effectively reach its medium-term targeted volumes of ethanol production and ethanol blending with a moderate expansion of sugarcane cropland. Increased sugarcane production can be achieved on existing agricultural land through the implementation of advanced farming systems and increased use of agricultural inputs. Further agricultural land expansions can be planned in regions with higher yield potentials, reducing the land use in other regions more than proportionally. This paper demonstrates that demands for ethanol and sugar production can be met by increasing yields from the current country-average of 55.3 tc/ha in 2019 to 85.7 tc/ha in 2030 and a cropland expansion from its current 1.726 thousand $\mathrm{km} 2$ in 2019 to 1.840 thousand $\mathrm{km} 2$ in 2030.

Advanced agricultural practices minimizing yield-limiting factors (irrigation and nutrient deficiencies) and yield-reducing factors (weds, pests and diseases) are necessary to narrow yield gaps. Although increased mechanization allows a reduction in production costs, it requires high-capital upfront investments and can lead to lower job creation in rural areas ${ }^{13}$. In addition, access to irrigation is pivotal to reduce yield gaps and one of the main elements to shift towards sustainable agriculture intensification. National efforts to increase the sustainability of biofuel production should focus on developing a system for innovation and knowledge transfer of advanced technologies and best practices to farmers ${ }^{11}$. Also, enabling policies facilitating access to affordable credit and insurance are required to allow capitalintensive investments in high-input mechanized agriculture.

The fact that most of the biorefinery infrastructure is yet to be built means opportunities exist for investments with greater efficiency. Therefore, this paper has also explored opportunities to increase emission savings and to add economic and energy value to sugarcane biomass residues (bagasse and sugarcane trash) through efficient processes to generate bioelectricity and second-generation biofuels. The optimal size and locations of biorefineries are identified for the minimization of the total system cost. This paper demonstrates that with current technological advancements in efficient cogeneration, it is costoptimal to invest in modern facilities to provide biofuel and export electricity surplus to the national grid. Biofuel support in the range of 8-10 US\$/GJ is required for investments on second-generation biofuel to be cost-competitive. 
Lastly, our work is a first attempt at evaluating the entire sugarcane-based ethanol production chain and quantifying opportunities on agricultural intensification and investments in advanced biorefineries in a least-cost optimization model. As repeatedly pointed out, several assumptions were made in order to model the processes and materials in the production chain, and we have attempted to describe as explicitly as possible the limitations of our methodology and data. Future research could build upon our work using more accurate and up-to-date data for many of the parameters we have used in our model. Particularly, better quantitative microdata on use of agricultural inputs and mechanization could be combined with socio-economic data to investigate the factors influencing agriculture intensification and technology adoption. In addition, further CLEWs nexus interactions, effects of climate change and environmental effects of indirect land-use change (iLUC) emissions could be explored, adding valuable insights to the overall understanding on the sustainability of ethanol production.

\section{Acknowledgements}

The research work has benefited from interactions with government officials and stakeholders during Capacity Building activities in Bolivia. The authors acknowledge the contributions in policy insights, information and knowledge-sharing from Gustavo Ayala and Neftali Chapi from the Ministry of Water and Environment (MMAyA), Silvia Fernández, Osmar Rosales, Carlos Sevillano, Daniela Bilbao and Mirna Mariscal from UDAPE, Shirley Canedo and Marcelo Velazquez from the Ministry of Energy, Abhishek Shivakummar, Joanna Félix and Eduardo Zepeda from UNDESA.

\section{Author Contributions and Funding}

Author contributions: J.G.P.B. carried the data gathering, model simulations, analysis, interpretation of results and produced the figures and tables of the manuscript. J.G.P.B., T.A. and S.U.J contributed with the conceptualization of the methods. S.U.J contributed to the data gathering and processing. D.K., F.G. and M.H. were involved in supervising the work and aid to the interpretation of results. J.G.P.B. wrote the manuscript with inputs from all authors.

Funding: This research was funded by the Swedish International Development Cooperation Agency 


\section{References}

1. Koçar, G. \& Civaş, N. An overview of biofuels from energy crops: Current status and future prospects. Renewable and Sustainable Energy Reviews 28, 900-916 (2013).

2. Scarlat, N. \& Dallemand, J. F. Recent developments of biofuels/bioenergy sustainability certification: A global overview. Energy Policy 39, 1630-1646 (2011).

3. de Oliveira Bordonal, R. et al. Sustainability of sugarcane production in Brazil. A review. Agron. Sustain. Dev. 38, 13 (2018).

4. Dahman, Y., Syed, K., Begum, S., Roy, P. \& Mohtasebi, B. Biofuels: Their characteristics and analysis. in Biomass, Biopolymer-Based Materials, and Bioenergy: Construction, Biomedical, and other Industrial Applications 277-325 (Elsevier, 2019). doi:10.1016/B978-0-08-102426-3.00014$\mathrm{X}$

5. Nanda, S., Rana, R., Sarangi, P. K., Dalai, A. K. \& Kozinski, J. A. A broad introduction to first-, second-, and third-generation biofuels. in Recent Advancements in Biofuels and Bioenergy Utilization 1-25 (Springer Singapore, 2018). doi:10.1007/978-981-13-1307-3_1

6. International Energy Agency. World Energy Outlook 2019. (OECD, 2019). doi:10.1787/caf32f3ben

7. OECD-FAO. Agricultural Outlook 2019-2028. Chapter 9. Biofuels. in (2019). doi:10.1787/agroutl-data-en

8. Goldemberg, J. The Brazilian biofuels industry. Biotechnology for Biofuels 1, 6 (2008).

9. Van-den-Berg, M. \& Singels, A. Modelling and monitoring for strategic yield gap diagnosis in the South African sugar belt. F. Crop. Res. 143, 143-150 (2013).

10. Mueller, N. D. et al. Closing yield gaps through nutrient and water management. Nature 490, 254257 (2012).

11. van Dijk, M. et al. Disentangling agronomic and economic yield gaps: An integrated framework and application. Agric. Syst. 154, 90-99 (2017).

12. Van-Wart, J. et al. Use of agro-climatic zones to upscale simulated crop yield potential. F. Crop. Res. 143, 44-55 (2013).

13. Cardoso, T. et al. Economic, environmental, and social impacts of different sugarcane production systems. Biofuels, Bioprod. Biorefining 12, 68-82 (2018).

14. Dias, M. O. S. et al. Biorefineries for the production of first and second generation ethanol and electricity from sugarcane. Appl. Energy 109, 72-78 (2013).

15. Khatiwada, D., Leduc, S., Silveira, S. \& McCallum, I. Optimizing ethanol and bioelectricity production in sugarcane biorefineries in Brazil. Renew. Energy 85, 371-386 (2016).

16. Dias, M. O. S. et al. Improving bioethanol production from sugarcane: Evaluation of distillation, thermal integration and cogeneration systems. Energy 36, 3691-3703 (2011).

17. Dourado Hernandes, T., Bof Bufon, V. \& Seabra, J. Water footprint of biofuels in Brazil : (2013). doi:10.1002/bbb

18. Vale Scarpare, F. et al. Sugarcane water footprint under different management practices in $\wedge /$ Jacar e watershed assessment Brazil : Tiet e. 112, 4576-4584 (2016).

19. Haro, M. E., Navarro, I., Thompson, R. \& Jimenez, B. Estimation of the water footprint of sugarcane in Mexico: is ethanol production an environmentally feasible fuel option? María Eugenia Haro , Ines Navarro, Ralph Thompson and Blanca Jimenez. J. Water Clim. Chang. 05, 70-80 (2014). 
20. Khatiwada, D. \& Silveira, S. Scenarios for bioethanol production in Indonesia: How can we meet mandatory blending targets? Energy 119, 351-361 (2017).

21. Khatiwada, D., Venkata, B., Silveira, S. \& Johnson, F. Energy and GHG balances of ethanol production from cane molasses in Indonesia. Appl. Energy 164, 756-768 (2016).

22. Seabra, J., Macedo, I., Chum, H., Faroni, C. \& Sarto, C. Life cycle assessment of Brazilian sugarcane products: GHG emissions and energy use. Biofuels, Bioproducs and Biorefining. 519532 (2011). doi:10.1002/bbb

23. Macedo, I. C., Seabra, J. E. A. \& Silva, J. E. A. R. Green house gases emissions in the production and use of ethanol from sugarcane in Brazil: The 2005/2006 averages and a prediction for 2020. Biomass and Bioenergy 32, 582-595 (2008).

24. van Ittersum, M. et al. Yield gap analysis with local to global relevance-A review. F. Crop. Res. 143, 4-17 (2013).

25. van Ittersum, M. \& Rabbinge, R. Concepts in production ecology for analysis and quantification of agricultural input-output combinations. F. Crop. Res. 52, 197-208 (1997).

26. Van-Loon, J. et al. Scaling agricultural mechanization services in smallholder farming systems: Case studies from sub-Saharan Africa, South Asia, and Latin America. Agric. Syst. 180, 102792 (2020).

27. Yadav, R. N. S., Yadav, S. \& Tejra, R. K. Labour Saving and Cost Reduction Machinery for Sugarcane Cultivation. Sugar Tech 5, 7-10 (2003).

28. Verma, S. R. Impact of Agricultural Mechanization on Production , Productivity , Cropping Intensity Income Generation and Employment of Labour. in Status of Farm Mechanization in India (ed. Indian Agri. Stat. Research Indian Agri. Stat. Research Institute) 133-153 (Indian Council of Agricultural Research, 2006).

29. Dias, M. O. S. et al. Improving second generation ethanol production through optimization of first generation production process from sugarcane. Energy 43, 246-252 (2012).

30. Birru, E., Erlich, C. \& Martin, A. Energy performance comparisons and enhancements in the sugar cane industry. Biomass Convers. Biorefinery 9, 267-282 (2019).

31. Birru, E. D. Process Utility Performance Evaluation and Enhancements in the Traditional Sugar Cane Industry. (2019).

32. Deshmukh, R., Jacobson, A., Chamberlin, C. \& Kammen, D. Thermal gasification or direct combustion? Comparison of advanced cogeneration systems inthe sugarcane industry. Biomass and Bioenergy 55, 163-174 (2013).

33. ISO. Cogeneration-opportunities in the world sugar industry. (2009).

34. Dias, M. O. S. et al. Second generation ethanol in Brazil: Can it compete with electricity production? Bioresour. Technol. 102, 8964-8971 (2011).

35. Mbohwa, C. Bagasse energy cogeneration potential in the Zimbabwean sugar industry. 28, 191204 (2003).

36. Nolte, G. E. USDA Foreign Agricultural Service. Global Agricultural Information Network. Bolivia Enters Ethanol Era. (2018).

37. YPFB. Bolivia ingresa a la era del biocombustible. (2018). Available at: https://www.ypfb.gob.bo/en/medio-ambiente/14-noticias/841-bolivia-ingresa-a-la-era-delbiocombustible-y-ypfb-dejará-de-importar-80-millones-de-litros-de-gasolina-2.html. (Accessed: 23rd May 2020)

38. Instituto Nacional de Estadísticas. Encuesta Nacional Agropecuaria. Superficie cultivada, producción y rendimiento. (2019).

39. Lobell, D. B., Cassman, K. G. \& Field, C. B. Crop Yield Gaps: Their Importance, Magnitudes, 
and Causes. Annu. Rev. Environ. Resour. 34, 179-204 (2009).

40. FAO. FAOSTAT. (2018). Available at: http://www.fao.org/faostat/en/\#rankings/countries_by_commodity. (Accessed: 16th November 2018)

41. Instituto Nacional de Estadistica, I. Censo Agropecuario 2013 Bolivia. (2015).

42. Cruz, C. H. B., Souza, G. M. \& Cortez, L. A. B. Biofuels for Transport. 215-244 (2014). doi:10.1016/B978-0-08-099424-6.00011-9

43. Howells, M. et al. OSeMOSYS: The Open Source Energy Modeling System. Energy Policy 39, 5850-5870 (2011).

44. Welsch, M. et al. Adding value with CLEWS - Modelling the energy system and its interdependencies for Mauritius. Appl. Energy 113, 1434-1445 (2014).

45. Pereira-Ramos, E. et al. The Climate Land Energy Water systems (CLEWs) Framework: A retrospective of activities and advances to 2019 - In Press. Environ. Res. Lett. (2020).

46. Ministerio de Medio Ambiente y Agua (MMAyA). Balance Hídrico Superficial de Bolivia 198081- 2015/16. (2017).

47. Ministerio del Agua. Plan Nacional de Desarrollo del Riego 2007-2011. (2007).

48. Odum \& T, H. Systems ecology; An introduction. (1983).

49. Nguyen, T. L. T., Gheewala, S. H. \& Garivait, S. Full chain energy analysis of fuel ethanol from cassava in Thailand. Environ. Sci. Technol. 41, 4135-4142 (2007).

50. Nguyen, T. L. T. \& Gheewala, S. H. Life cycle assessment of fuel ethanol from cane molasses in Thailand. Int. J. Life Cycle Assess. 13, 301-311 (2008).

51. Khatiwada, D. \& Silveira, S. Greenhouse gas balances of molasses based ethanol in Nepal. $J$. Clean. Prod. 19, 1471-1485 (2011).

52. Khatiwada, D. \& Silveira, S. Net energy balance of molasses based ethanol: The case of Nepal. Renew. Sustain. Energy Rev. 13, 2515-2524 (2009).

53. Kahil, T. et al. A Continental-Scale Hydroeconomic Model for Integrating Water-Energy-Land Nexus Solutions. Water Resour. Res. 54, 7511-7533 (2018).

54. Observatorio Agroambiental y Productivo \& Viceministerio de Desarrollo Rural y Agropecuario. Agricultural production costs per crop for mechanized, semi-mechanized and traditional production systems in departments of Bolivia. (2014). Available at: http://www.observatorioagro.gob.bo/index.php?variable=19. (Accessed: 22nd September 2020)

55. Bernués, A. \& Herrero, M. Farm intensification and drivers of technology adoption in mixed dairycrop systems in Santa Cruz, Bolivia. Spanish J. Agric. Res. 6, 279-293 (2008).

56. MDRyT. Compendio Agropecuario 2012 Observatorio Agroambiental y Productivo. (2012).

57. Cuentas, L. Producción y Política Azucarera. Scielo. Fides Ratio- Rev. Difusión Cult. y científica la Univ. La Salle en Boliv. 5, (2012).

58. Fischer, G. et al. Global Agro-ecological Zones (GAEZ v3.0)- Model Documentation. (2012).

59. Allen, R. G., Pereira, L. S., Raes, D. \& Smith, M. Crop evapotranspiration - Guidelines for computing crop water requirements - FAO Irrigation and drainage paper 56. in 1-15 (1998).

60. Yates, D., Sieber, J., Purkey, D. \& Huber-Lee, A. WEAP21-A demand-, priority-, and preference-driven water planning model: part 1: model characteristics. Water Int. 30, 487-500 (2005).

61. Maidment, D. R. Handbook of hydrology (Vol.1). (McGraw-Hill, 1993).

62. Perez, R. Feeding pigs in the tropics. (1997). 
63. Khatiwada, D., Seabra, J., Silveira, S. \& Walter, A. Power generation from sugarcane biomass e A complementary option to hydroelectricity in Nepal and Brazil. Energy 48, 241-254 (2012).

64. Hassuani, S., Leal, M. \& Macedo, I. Biomass Power Generation. Sugar Cane Bagasse and Trash. UNDP-UN and Centro de Tecnologia Canavieira-CTC (2005).

65. Cardoso, T. F. et al. Biomass and Bioenergy. A vertical integration simpli fi ed model for straw recovery as feedstock in sugarcane biorefineries. 81, 216-223 (2015).

66. World Energy Council- Bioenergy. World Energy Resources Bioenergy 2016. (2017).

67. UNAGRO. Memoria Institucional Unagro 2016-2018. (2019).

68. EASBA. Memoria Institucional Empresa Azucarera San Buenaventura. (2018).

69. IAGSA. Memoria Anual Ingenio Azucarero Guabira S.A. (2018).

70. Aguai. Memoria Institucional Ingenio Sucroalcoholero Aguai. (2018).

71. Southgate, D. The Causes of Land Degradation along 'Spontaneously' Expanding Agricultural Frontiers in the Third World. Land Econ. 66, 93-101 (1990).

72. Barbier, E. B. \& Hochard, J. P. Land degradation and poverty. Nat. Sustain. 1, 623-631 (2018).

73. OECD-FAO. Agricultural Outlook 2017-2026. Commodity Snapshots. (2017). Available at: http://www.fao.org/3/a-BT092e.pdf.

74. Ministerio de Hidrocarburos. Balance Energético Nacional 2006-2018. (2019).

75. Estado Plurinacional de Bolivia. Intended Nationally determined contribution from the Plurinational State of Bolivia,. (2015).

76. Flamos, A. et al. Bioenergy Options in the Industrialized and Developing World and Opportunities for the Clean Development Mechanism DEVELOPING WORLD AND OPPORTUNITIES FOR THE CLEAN DEVELOPMENT MECHANISM. 5075, (2010).

77. Mcnish, T., Jacobson, A., Kammen, D., Gopal, A. \& Deshmukh, R. Sweet carbon : An analysis of sugar industry carbon market opportunities under the clean development mechanism. Energy Policy 37, 5459-5468 (2009). 
Figures

Area $\longrightarrow$ Yield

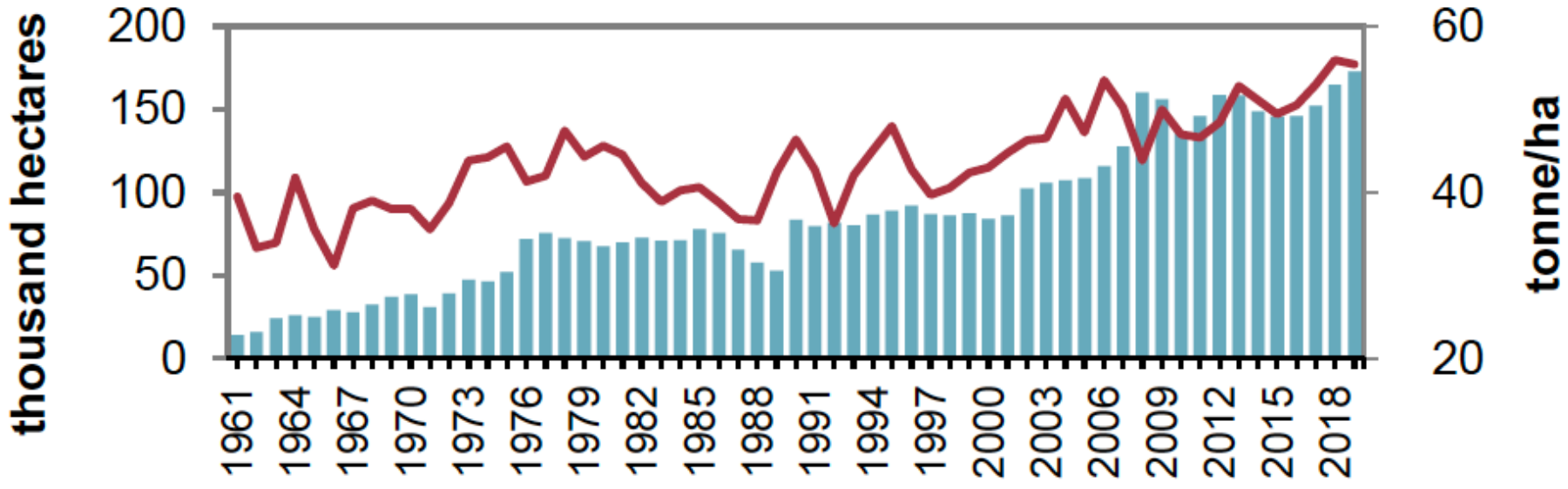

Figure 1

Historical data on the harvested area in primary axis and average yields in the secondary axis

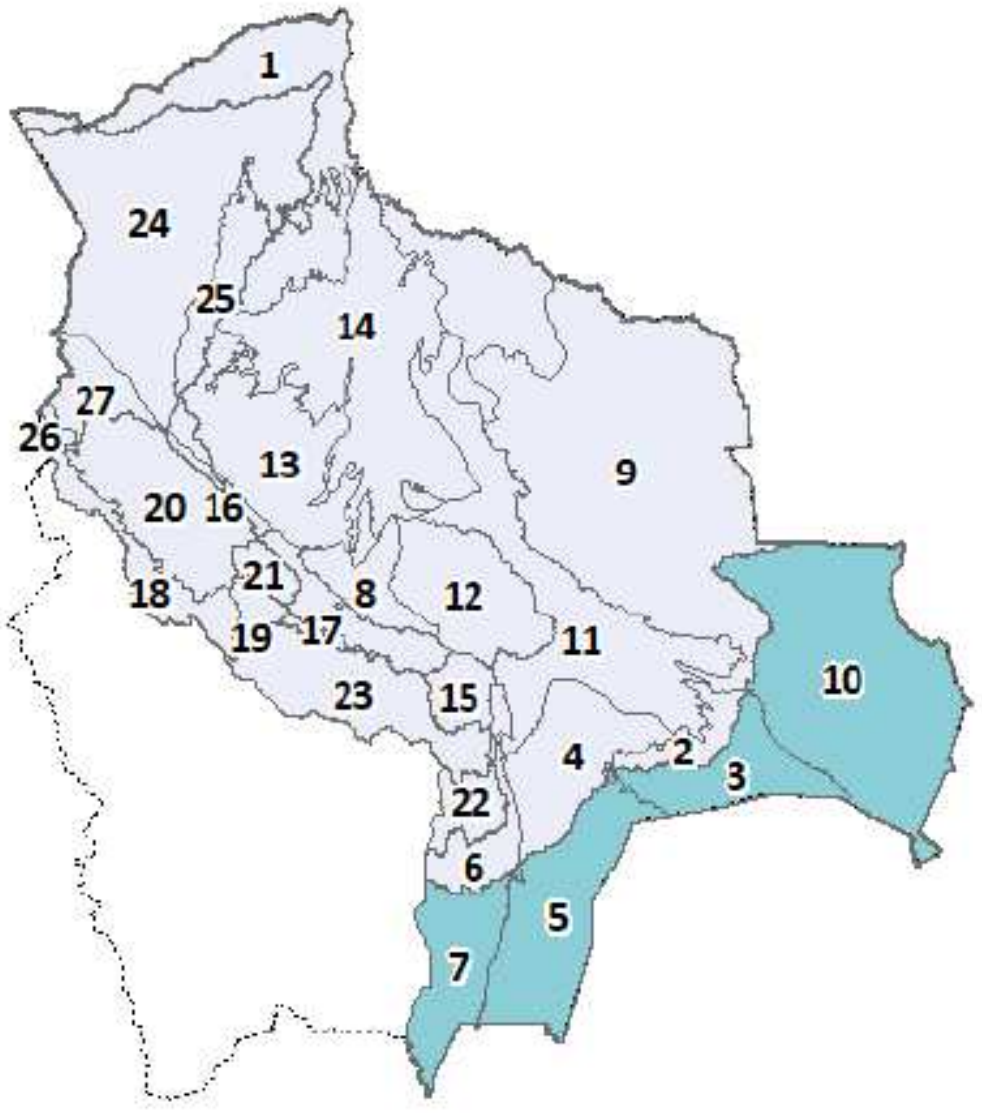

\section{Legend}

$\square$ Administrative limits

$\square$ Regions

Hydrogeo logical units

Watersheds

Macro river-basins

Altiplano

Amazon

La Plata

Figure 2 
Map of the harmonized zonation scheme with 27 regions. Note that the regions with no sugarcane crop potential were removed from the study.

\section{System boundaries}

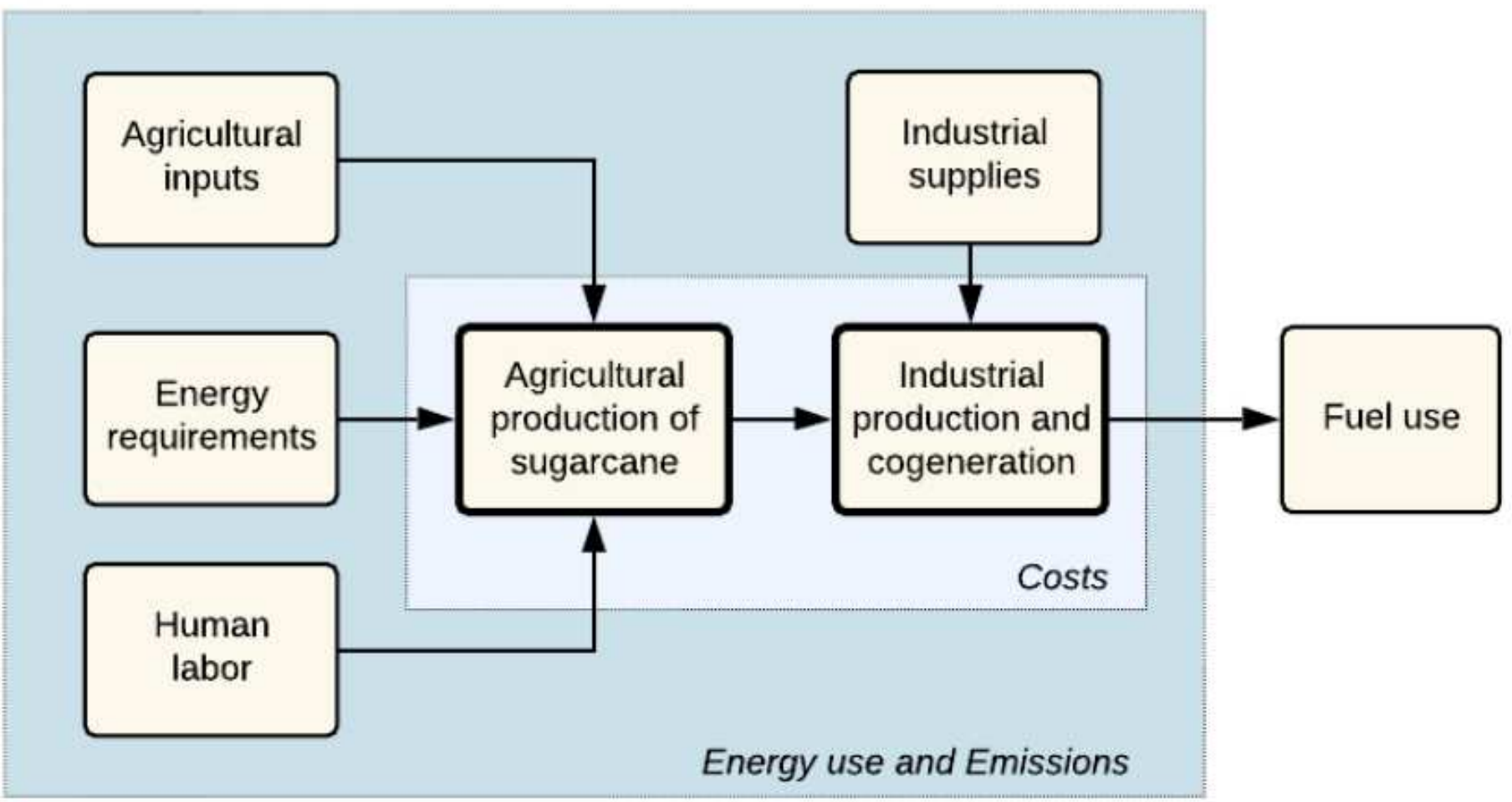

\section{Figure 3}

Scheme of the system boundaries used in the ethanol lifecycle assesment

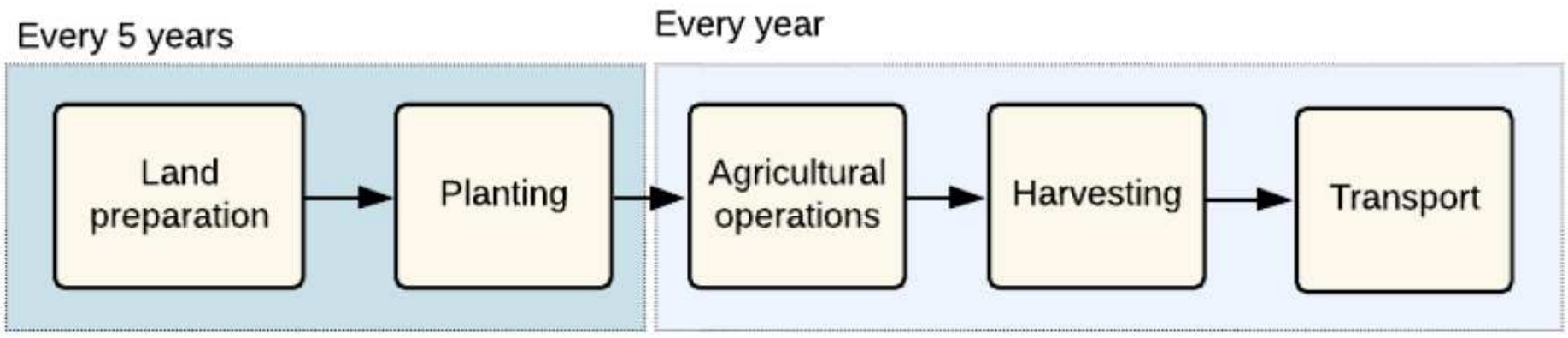

\section{Figure 4}

Scheme of the processes modelled in the agricultural production unit 


\section{CONVENTIONAL BIOREFINERY}

a)

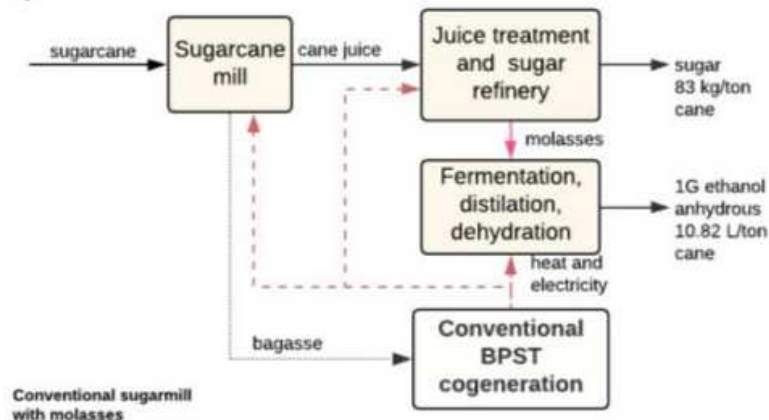

b)

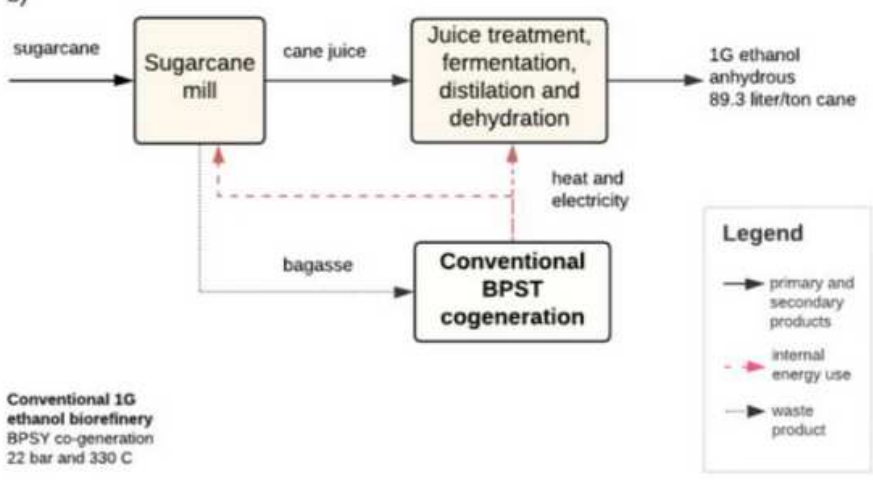

ADVANCED/EFFICIENT BIOREFINERY

c)

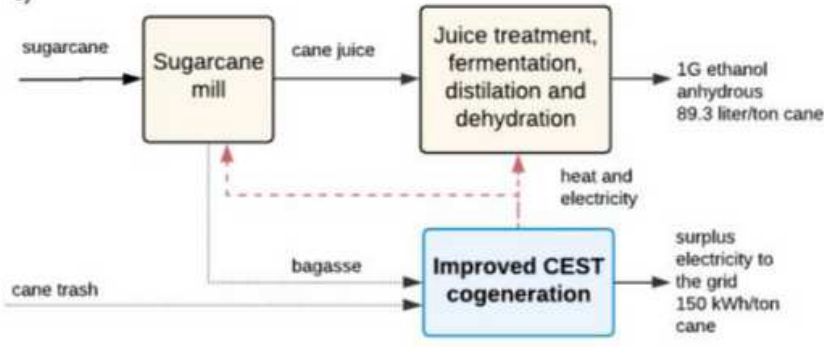

Biorefinery with

maximization of surplus

electricity

90 bar and $520 \mathrm{C}$

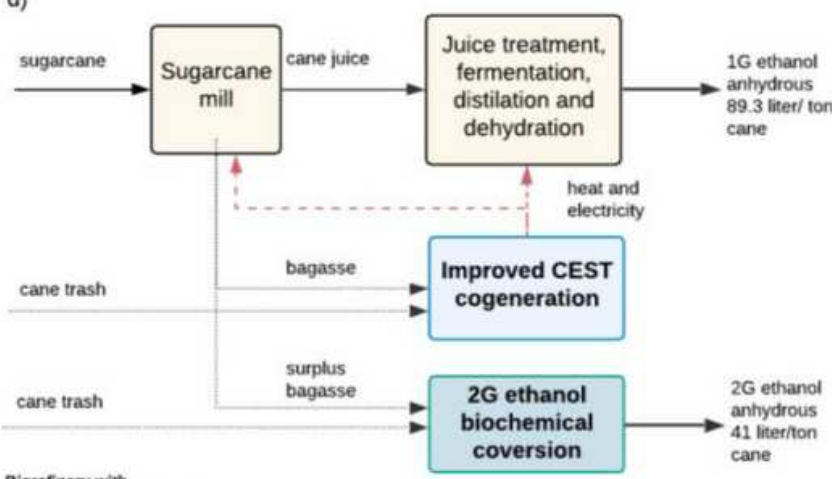

Biorefinery with

production of ethanol

CEST co-gen

90 bar and $520 \mathrm{C}$.

\section{Figure 5}

Biorefinery technological options. a) Biorefinery for $1 \mathrm{G}$ ethanol production using sugarcane molasses, conventional CHP plant (no sugarcane trash recovery), b) Biorefinery for $1 \mathrm{G}$ ethanol production using sugarcane juice, conventional CHP plant (no sugarcane trash recovery), c) Biorefinery for $1 \mathrm{G}$ ethanol production with efficient CHP and export of surplus electricity generation (50\% of sugarcane trash recovery), d) Biorefinery for $1 \mathrm{G}$ and $2 \mathrm{G}$ ethanol production with efficient $\mathrm{CHP}$ ( $50 \%$ of sugarcane trash recovery). Further details on the conversion chain are detailed in Section Error! Reference source not found. in Supplementary Materials 


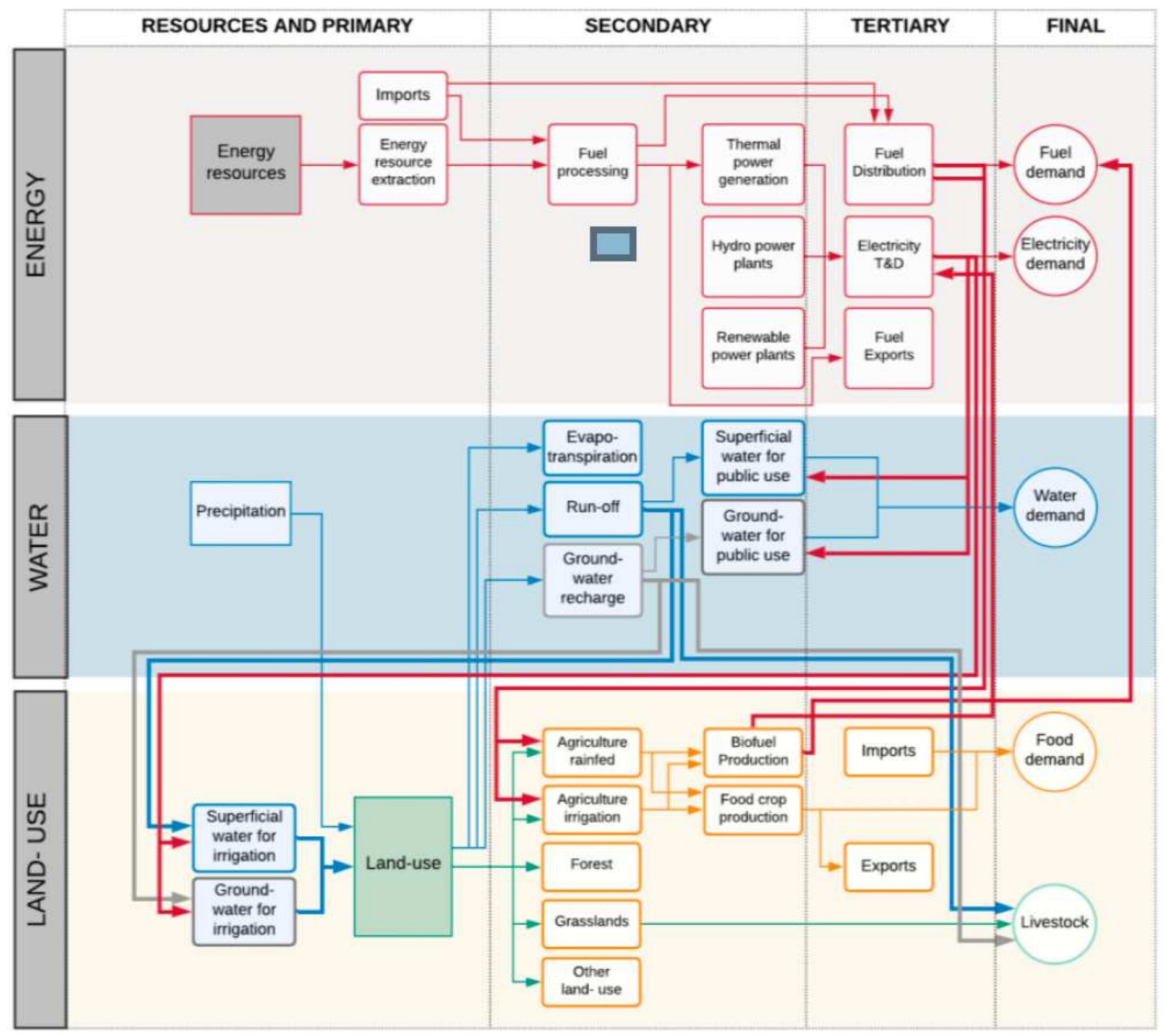

\section{LEGEND}

$\begin{array}{lll}\longrightarrow \text { Energy } & \longrightarrow \text { Ground water } \longrightarrow \text { Land-use } & \longrightarrow \text { Nexus interaction } \square \text { Technology } \\ \text { Water } & \longrightarrow \text { Crop products } \longrightarrow \text { Single system flow } \square \text { Resource }\end{array}$

\section{Figure 6}

Simplified representation of the systems modelled and the nexus interactions. 
Production costs per tonne

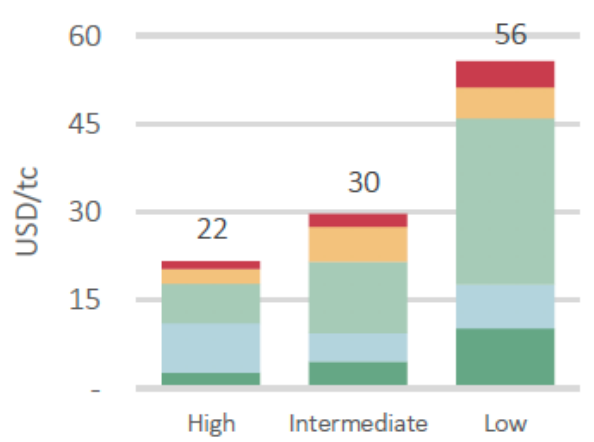

Emissions

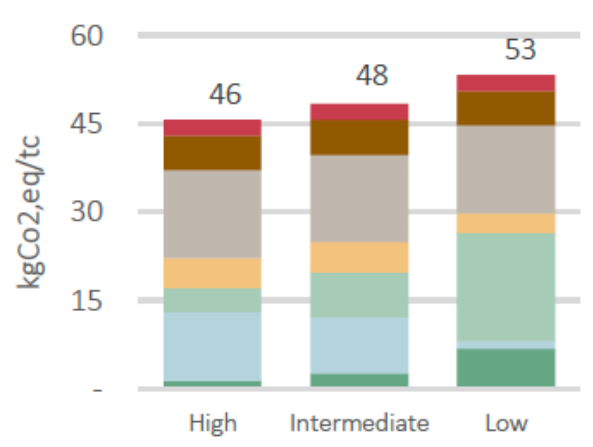

Production costs per hectare
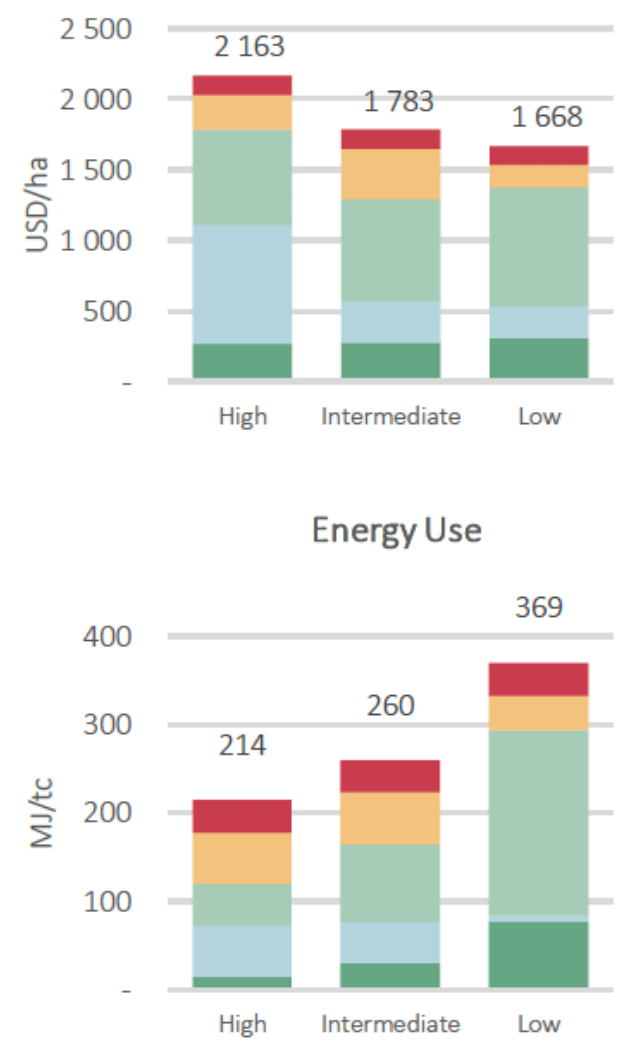

- Irrigation

Transportation

Harvesting

Agriculture inputs

- Sugarcane farming

Irrigation

Transportation

Harvesting

Agriculture inputs

- Sugarcane farming

\section{Figure 7}

Comparison of the lifecycle production costs per unit of production and per unit of harvested area, emissions and energy use of sugarcane cultivated under high, intermediate and low input levels. - Note that the cost estimates vary in every region according to their potential yields. Average yields are used in the charts for illustrative purposes: $100 \mathrm{tc} / \mathrm{ha}$ for high-inputs, $70 \mathrm{tc} / \mathrm{ha}$ for intermediate inputs and 30 tc/ha for low-inputs. Only results for irrigated agriculture are presented. - Note that the charts do not show data for production with trash recovery. Additional costs of harvesting and transport are introduced together with reduced emissions estimated in 13. 
a)

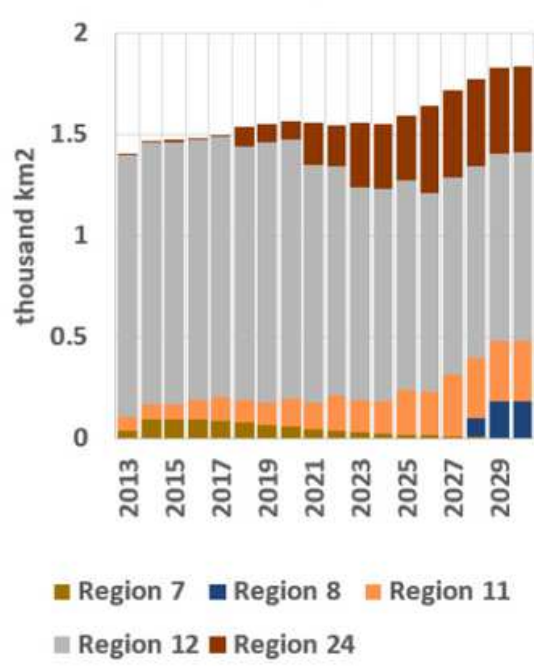

PRODUCTION

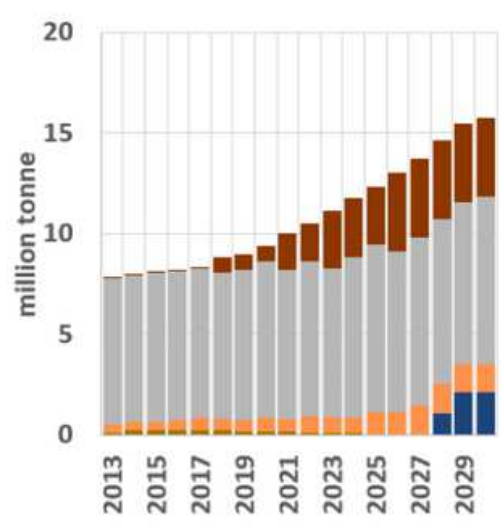

- Region 7 Region 8 - Region 11

= Region 12 = Region 24
LAYOUT
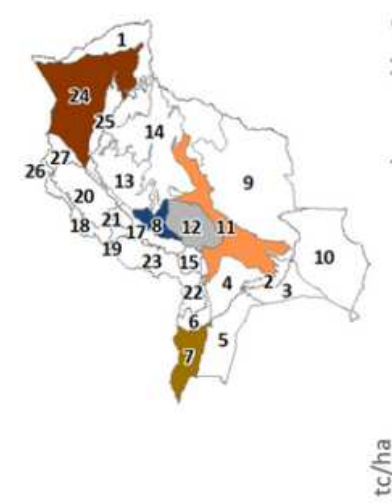

b) AREA

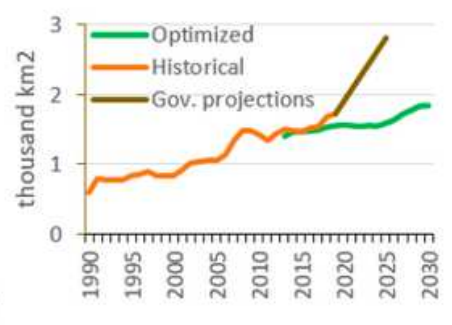

YIELD

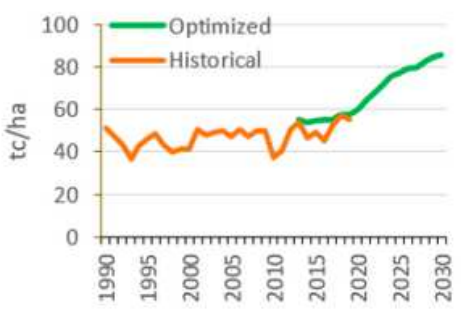

\section{Figure 8}

Optimization results for a) Cultivated area in main producing Regions, b) Annual production of main producing regions, c) Comparison of agriculture area national averaged yield between government projections and the optimization results

Cropland area by input level

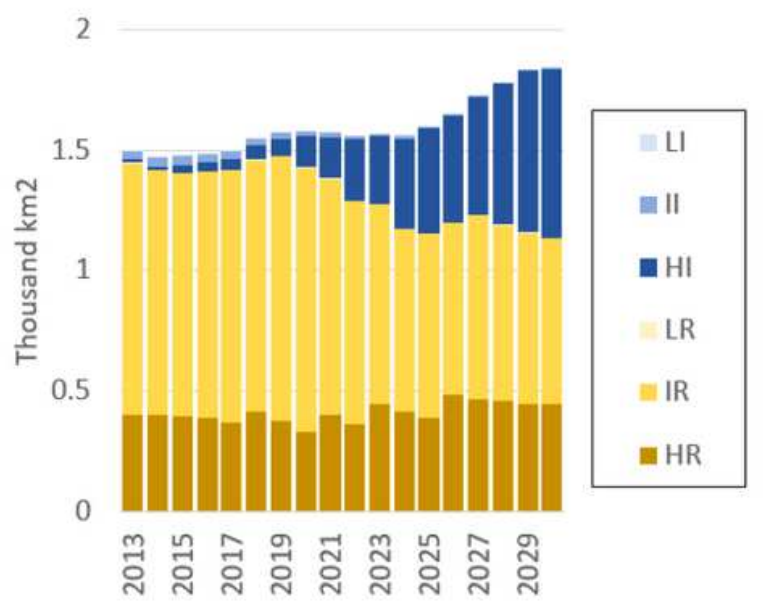

Investments in new cropland
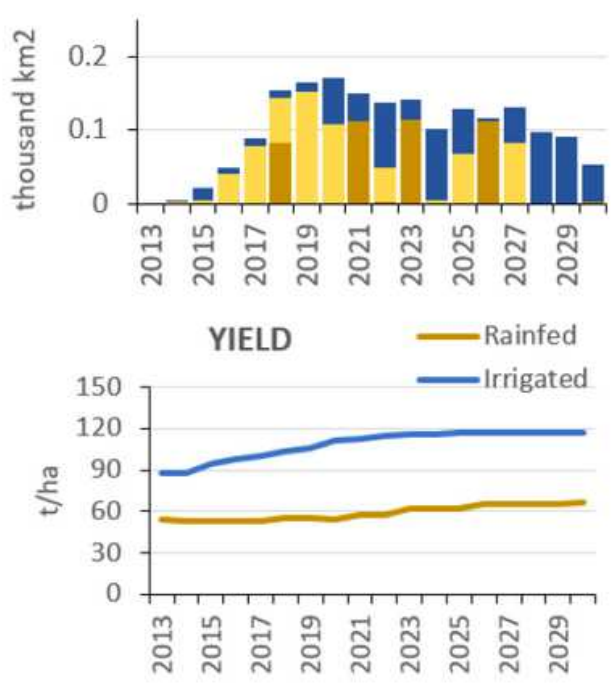

AREA

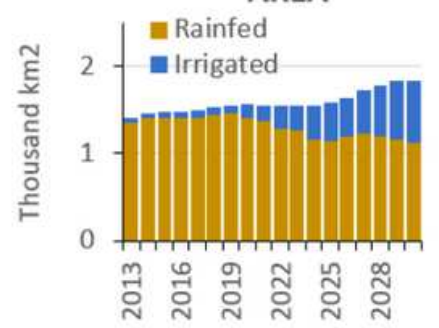

PRODUCTION

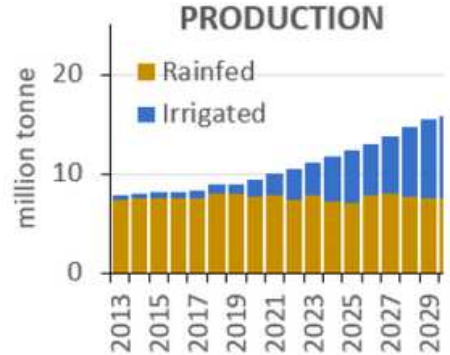

\section{Figure 9}

a) Results of the sugarcane agricultural land by input level, b) agricultural land expansion by input level, c) Accumulated area and production for water use per category. Management input levels acronyms, CDALI (low-inputs with irrigation), CDAll (intermediate-inputs with irrigation), CDARHI (high-inputs with irrigation), CDALR (low-inputs and rainfed), CDAIR (intermediate inputs and rainfed), CDAHR (high-inputs and rainfed). 


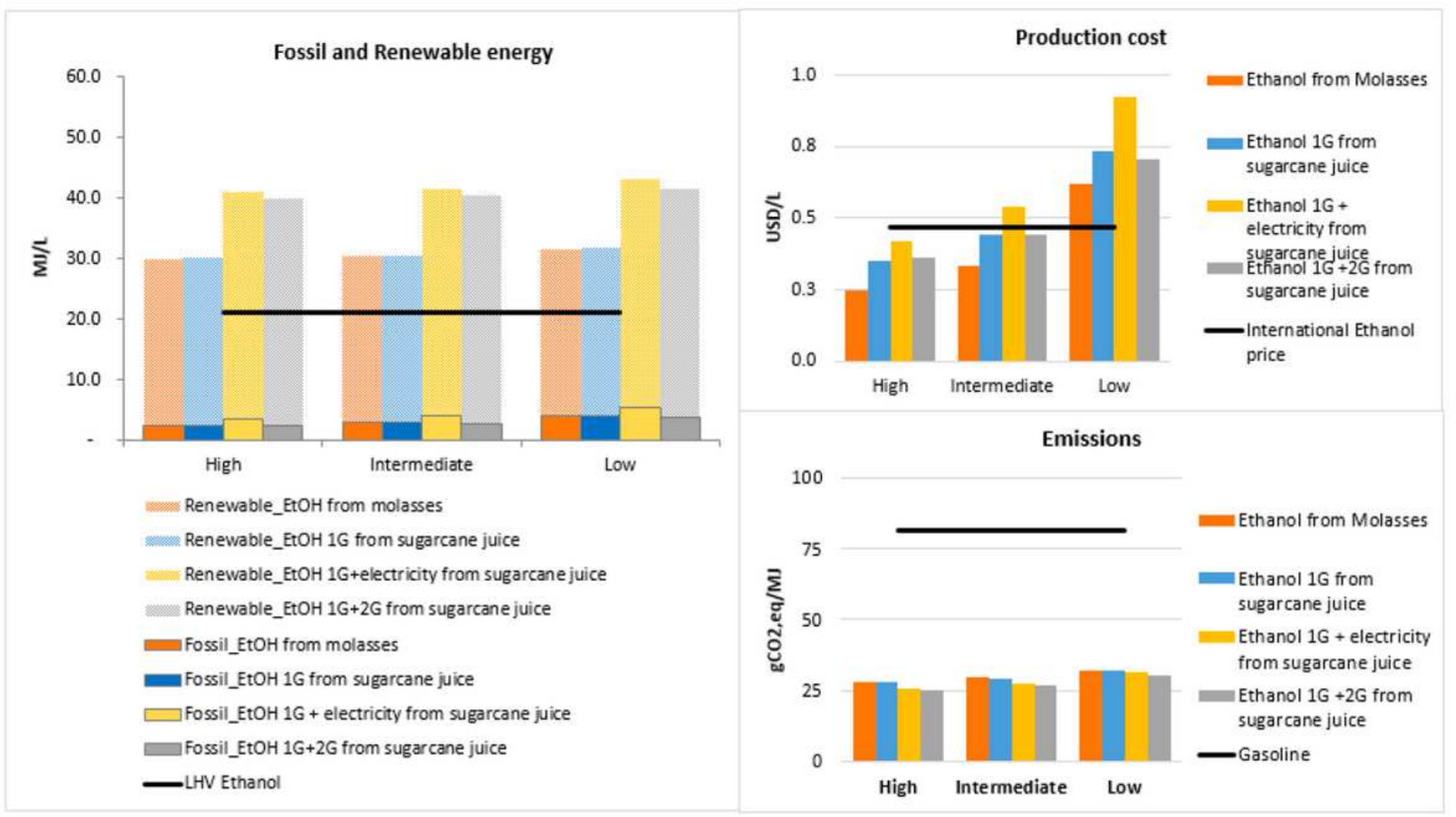

\section{Figure 10}

Comparison of the lifecycle energy, production costs and emissions. - For ethanol produced from molasses, emissions, energy and costs from the upstream operations (cultivation, harvesting and transport) are partitioned as per economic allocation following a methodology illustrated in 20. - Note that the values presented in this illustrative example include yields of $100 \mathrm{tc} / \mathrm{ha}, 70 \mathrm{tc} / \mathrm{ha}$ and $30 \mathrm{tc} / \mathrm{ha}$ for high, intermediate and low-input production. The lifecycle costs, energy and emissions presented in this figure will vary for every region due to yield differences for each agricultural production type.

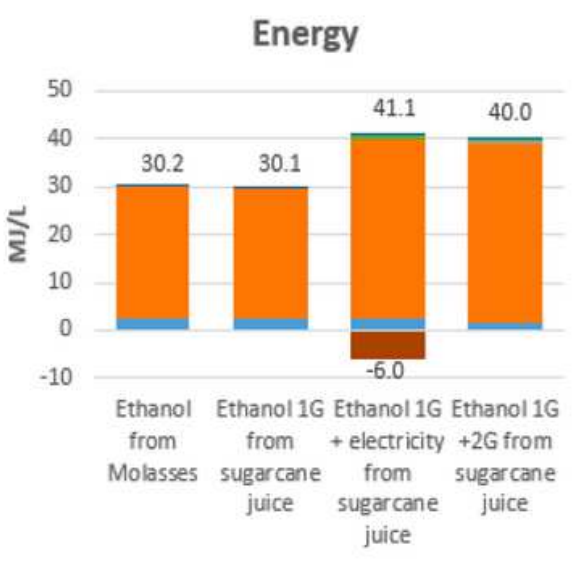

-Electricity surplus sales

Enzyme

Eugarcane production and transportation

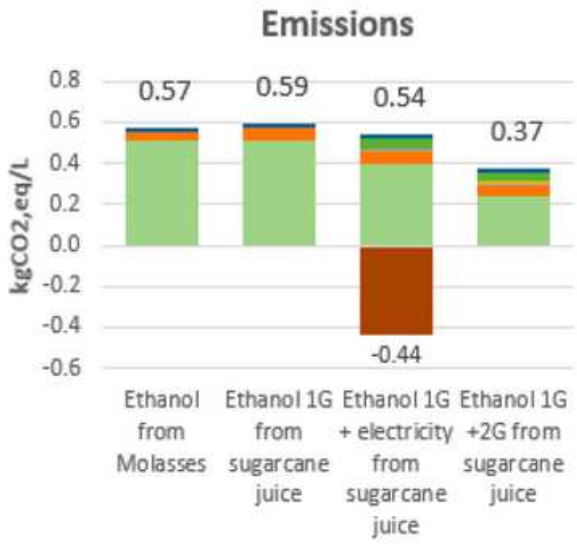

Ethanol transport and distribution

E Trash recovery
Production cost

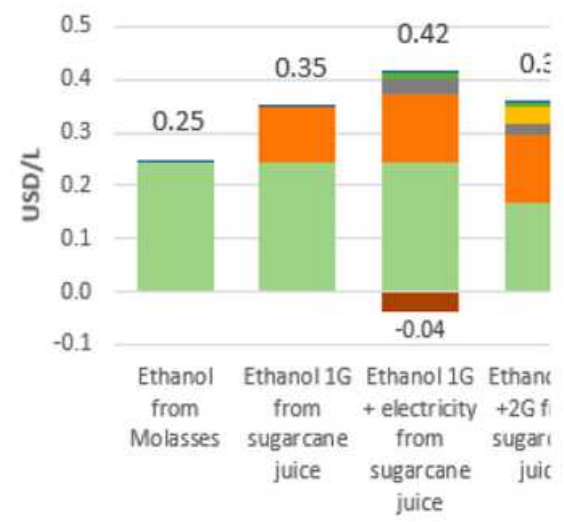

- Trash transport

- Processing to ethanol* 


\section{Figure 11}

Comparison of the lifecycle energy use, emissions and costs of the four biorefinery configurations. Sugarcane feedstock produced with High inputs with irrigation is used. Avoided emissions from electricity surplus sales are calculated considering $1.68 \mathrm{kWh} / \mathrm{L} \mathrm{EtOH}$ (see the balance in Error! Reference source not found., assuming that bioelectricity displaces gas-fired generation in the grid (emission intensity of $90.93 \mathrm{gCO} 2 / \mathrm{MJ}$ ). Revenues from electricity surplus sales are accounted for considering a revenue at marginal generation costs ( $16.71 \mathrm{USD} / \mathrm{kWh})$.

EMISSIONS

800

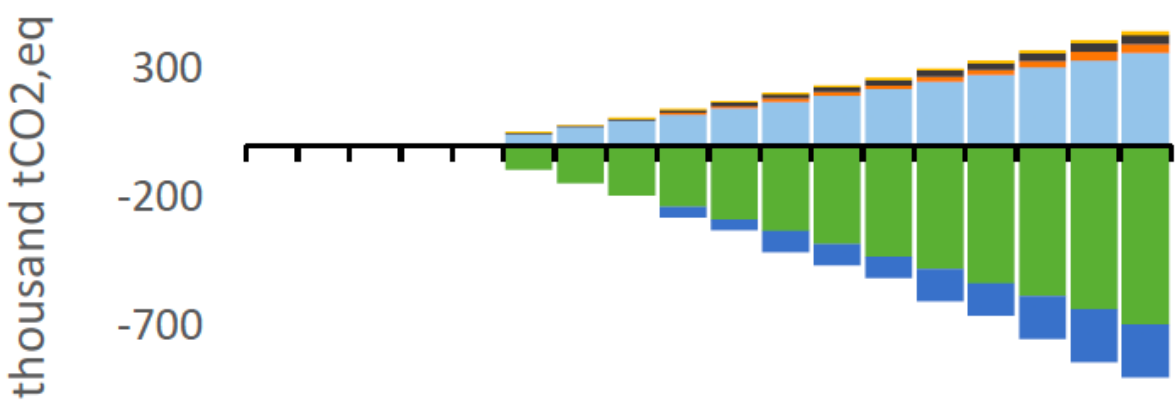

Ethanol transport and distribution

- Processing to Ethanol

- Trash recovery and transport

Sugarcane production

- Avoided electricity emissions

- Avoided gasoline emissions

$-1200$

m

Figure 12

Emissions from ethanol production and avoided emissions from gasoline and electricity consumption 


\section{ACCUMULATED NEW INVESTMENTS}

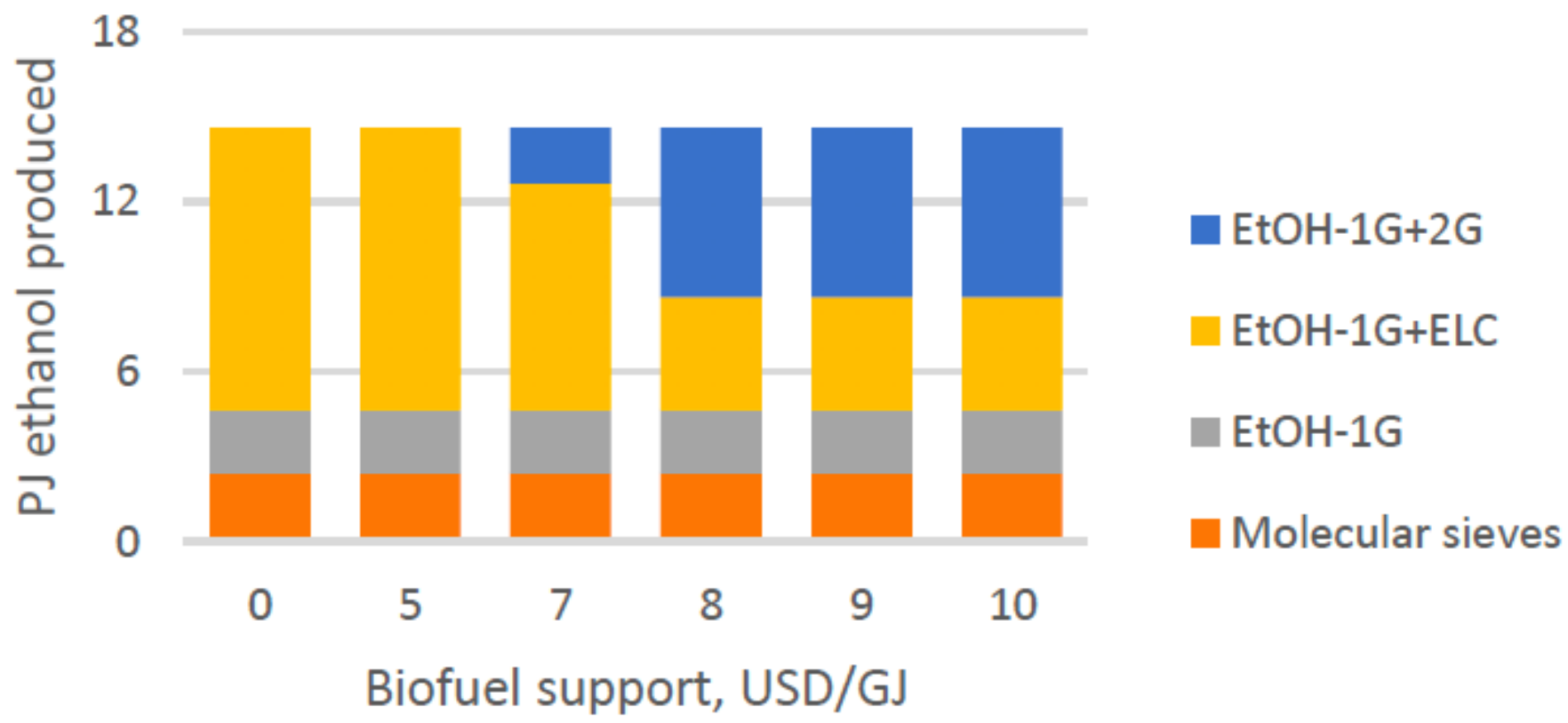

Figure 13

Accumulated energy production (or technology activity) in PJ and b) accumulated new capacity of biorefineries in units of PJ of ethanol produced Note.- Molecular sieves are installed on existing sugarmills producing hydrous ethanol to produce anhydrous ethanol. 
a)

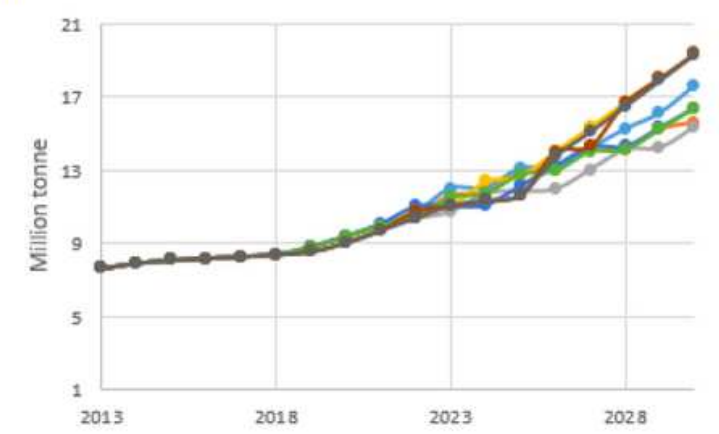

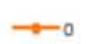

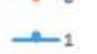

$\rightarrow-2$

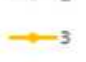

$\rightarrow$

$\rightarrow$

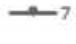

b)

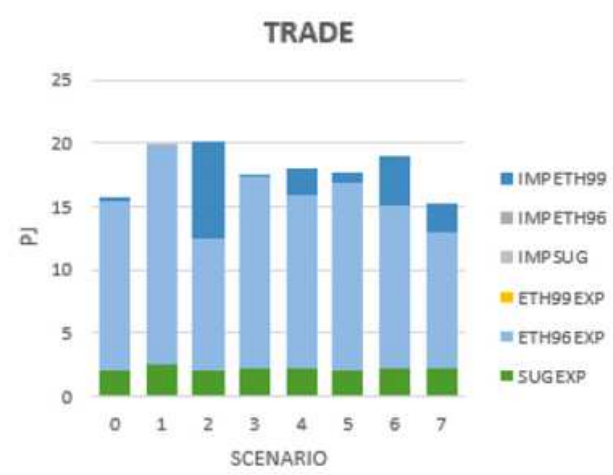

c)

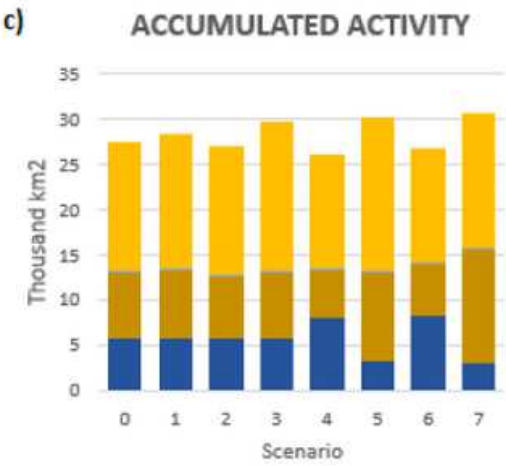

SUGARCANE AREA

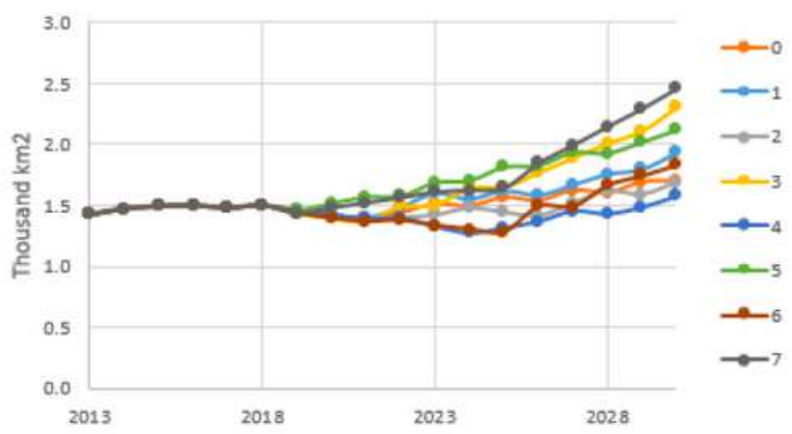

ACCUMULATED NEW CAPACITY

3

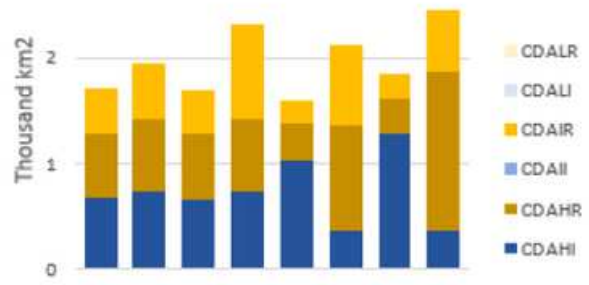

CDAHI

\section{Figure 14}

Results from sensitivity scenarios. a) Sugarcane area and production. b) Commodity trade (imports and exports). c) Accumulated harvested area (activity) by input level and accumulated new investments by input level (new capacity)

\section{Supplementary Files}

This is a list of supplementary files associated with this preprint. Click to download.

- 3.SupplementaryMaterials.pdf 